Research Article

\title{
Spatial and Temporal Variations of Terrestrial Evapotranspiration in the Upper Taohe River Basin from 2001 to 2018 Based on MOD16 ET Data
}

\author{
Lizhen Cheng $\mathbb{D},{ }^{1,2}$ Meixue Yang $\mathbb{D}^{1},{ }^{1}$ Xuejia Wang $\mathbb{D},{ }^{1}$ and Guoning Wan ${ }^{1}$ \\ ${ }^{1}$ State Key Laboratory of Cryospheric Science, Northwest Institute of Eco-Environment and Resources, \\ Chinese Academy of Sciences, No. 320 Donggang West Road, Lanzhou 730000, Gansu Province, China \\ ${ }^{2}$ University of Chinese Academy of Sciences, No. 19A Yuquan Road, Beijing 100049, China \\ Correspondence should be addressed to Meixue Yang; mxyang@lzb.ac.cn and Xuejia Wang; xjwang@lzb.ac.cn
}

Received 29 November 2019; Revised 14 July 2020; Accepted 7 August 2020; Published 28 August 2020

Academic Editor: Theodore Karacostas

Copyright (C) 2020 Lizhen Cheng et al. This is an open access article distributed under the Creative Commons Attribution License, which permits unrestricted use, distribution, and reproduction in any medium, provided the original work is properly cited.

Evapotranspiration (ET) is an essential component of watershed hydrological cycle. Spatial-temporal variations analyses of evapotranspiration and potential evapotranspiration (PET) have remarkable theoretical and practical significances for understanding the interaction between climate changes and hydrological cycle and optimal allocation of water resources under global warming background. The MODIS-estimated ET agreed well with basin evapotranspiration from water balance principle methods in the study. The spatiotemporal variations results based on MOD16 ET data showed the following: (1) multiyear mean ET and PET were $464.2 \mathrm{~mm}$ and $1192.2 \mathrm{~mm}$, and annual ET showed an upward trend at a rate of $3.48 \mathrm{~mm} / \mathrm{a}$, while PET decreased significantly at a rate of $-8.18 \mathrm{~mm} / \mathrm{a}$. The annual ET trend showed a complemental relationship with PET; (2) at the seasonal scale, ET was highest in summer and least in winter, while PET was higher in spring and summer. The change of ET and PET in spring and summer had a great contribution to the annual variations; (3) ET and PET in the northern part were significantly stronger than those in the western and southern parts; (4) ET in cropland increased significantly, while PET decreased obviously in grass and forest; (5) changes of ET and PET were closely related to climatic factors. The rise in temperature caused the increase in ET and the decrease of wind speed contributed more to the decrease in PET. The results can provide a scientific basis for water resources planning and management.

\section{Introduction}

Evapotranspiration (ET) is a critical component of global hydrological cycle and energy balance, which consumes $60 \%-65 \%$ of precipitation [1]. It is composed of not only evaporation from soil surface and plant transpiration but also evaporation from water bodies and sublimation from snow and glacier surface [2]. Also, potential evapotranspiration (PET) is defined as the evapotranspiration capability under the conditions of actively growing and adequate water, which is one of the most important hydrological variables for scheduling irrigation systems and preparing input data to hydrological water balance models for a region or basin [3-5]. Over the past few decades, numerous theories and practices have already proven that ET and PET involved complex interactions between water and energy fluxes and also were highly influenced by variations of meteorological factors due to combined effects of climate change and ecosystem management $[6,7]$. Since ET is difficult to measure directly, the accurate estimation of ET remains a problematic task for the study of climate changes and hydrological processes [8].

Traditionally, ET can be measured by using land surface parameters (temperature, net land surface radiation, vegetation index, and soil moisture) at global scale, water balance, or crop growth models for crop ET [9]. However, these conventional methods cannot represent large-scale terrestrial evapotranspiration due to heterogeneity of land surface and complexity of hydrologic processes [10]. Currently, we have witnessed significant developments in the field of 
satellite evapotranspiration estimation, which can capture land surface information from larger geographic extents and provide cost-effective, efficient, up-to-date information for retrieving ground parameters at global scale [11, 12]. A variety of satellite-based products have provided valuable evapotranspiration data sources to research at different spatial scales, especially for regions with lack of and sparse observations $[13,14]$.

To estimate global evapotranspiration, MOD16 algorithm has combined satellite data such as land cover, albedo, leaf area index (LAI), solar radiation, air temperature, and actual vapor pressure deficit from reanalysis data [15-17]. Several researchers have validated MODIS ET data in many countries and found that MODIS estimation is better to monitor ET at large scale $[18,19]$. For example, MOD16 ET products have been verified by comparing observed ET in North China Plain and other regions using in situ observations, and results showed that MOD16 ET data can provide reasonable accuracy [20]. Ma et al. [21] evaluated MODIS ET data using in situ observations in the Three Gorges Reservoir region of China and found that MODIS well captured the seasonal variability of ET and had a better performance. Wang et al. [22] compared the consistency between observed pan-PET and MOD16 over Hebei province and found that the performances of linear fitting in ET and PET were both better $(P<0.001$ and slope $=1.02)$. Yet, few studies focus on the performance of MODIS ET data in the upper Taohe River basin, located in the transition zone of the two major geomorphic units of China, Qinghai-Tibet Plateau and Loess Plateau. Therefore, this study selected MODIS MOD16 ET data to investigate the spatial and temporal characteristics of ET and PET and their variations under different land-use types, as well as their relationship with climatic factors in this basin from 2001 to 2018, aiming at providing a scientific basis for the reasonable allocation of water resources.

\section{Study Area and Data}

2.1. Study Area. Taohe River is a larger tributary of the upper Yellow River in Northwest China (Figure 1), originating from Xiqing Mountains in the south Qinghai province and flowing into Yellow River in Liujiaxia reservoir of Gansu province. Taohe River basin, with a total drainage area of 25 $527 \mathrm{~km}^{2}$, lies in the transition zone of the two major geomorphic units of China, Qinghai-Tibet Plateau and Loess Plateau [23]. It is asymmetric and accumbent " $\mathrm{L}$ " shaped, and the terrain is high in southwest area and low in northeast area. As there are significant differences in geomorphic, climatic, and hydrological features among each subriver section, upper Taohe River basin was split and selected as the study basin, which shoulders the water allocation task by Taohe River Diversion Project to downstream areas suffering water-shortage crisis.

The upper Taohe River basin $\left(101^{\circ} 36^{\prime}-104^{\circ} 04^{\prime} \mathrm{E}\right.$, $\left.34^{\circ} 06^{\prime}-35^{\circ} 01^{\prime} \mathrm{N}\right)$, with a total area of approximately $14976 \mathrm{~km}^{2}$, is mainly located in Gannan Plateau which is a margin part of Qinghai-Tibet Plateau. This region is dominated by relatively high attitude plateaus and mountains, at elevations ranging from 2219 to $4854 \mathrm{~m}$ (above sea level) (Figure 1). Plateaus occupy most part of study area and mountains mainly distributed in the extremely higher elevation regions. Besides, residential area is distributed in the central and northeast parts. According to important influence from solar radiation, temperature, and wind speed controlled by different topography and land use on ET and PET, the study region is divided into three zones: source region (west zone), left bank of river (north zone), and right bank of river (south zone).

The study area features an altitudinal cold humid and semihumid climate, being very cold in winter with snowfall and warm and rainy in summer [24]. Average temperature and precipitation vary from $0^{\circ} \mathrm{C}$ to $4^{\circ} \mathrm{C}$ and from 400 to $700 \mathrm{~mm}$, respectively. Approximately more than $65 \%$ precipitation concentrates on June and October constituting major sources of runoff over Taohe River basin [25]. Annual runoff reached 4.69 billion $\mathrm{m}^{3}$ (from 1951 to 2010) and accounted for $8.08 \%$ of Yellow River's total runoff [23]. Nearly $65 \%$ runoff concentrated on July and October, which is similar to precipitation. There is plentiful precipitation in the west part influenced by the Indian Ocean monsoon and terrain rain, while the northeast part is short of water [26], resulting in a clear difference over areas in the upper Taohe River basin.

In addition, Taohe River Diversion Project is one of the most important projects in Northwest China and is responsible for water allocation to several counties in the middle and northeast of Gansu province. Currently, continuous increasing trend of temperature and fluctuant variations of precipitation caused runoff to rapidly decrease and even exacerbated water crisis for downstream basin [25]. Therefore, it is urgent to investigate spatial and temporal characteristics of ET in upper Taohe River basin under the global warming background, which is important for exploring regional climate change and hydrological circle and also plays a fundamental role in water resource conservation and allocation.

2.2. Data. This study used remotely sensed ET, PET, landcover/use data, precipitation, and observed runoff data to understand spatial and temporal distribution of ET. To understand the causes of ET variability, it was important to use land-cover and climatic data such as precipitation, temperature, wind speed, relative humidity, and solar radiation as well.

2.2.1. Remotely Sensed Data. The MODIS instrument was developed by NASA and launched on Terra satellite in December 1999 and on Aqua satellite in May 2002 [27]. MODIS collects information both in the morning and in the afternoon as Terra passes from north to south across the equator in the morning and Aqua passes from south to north in the afternoon. MODIS data is provided by Numerical Terradynamic Simulation Group (NTSG) of the University of Montana, USA (http://www.ntsg.umt.edu/project/ mod16\#data-product). This study used updated MOD16 A2 Collection 6 Version 2 evapotranspiration products 


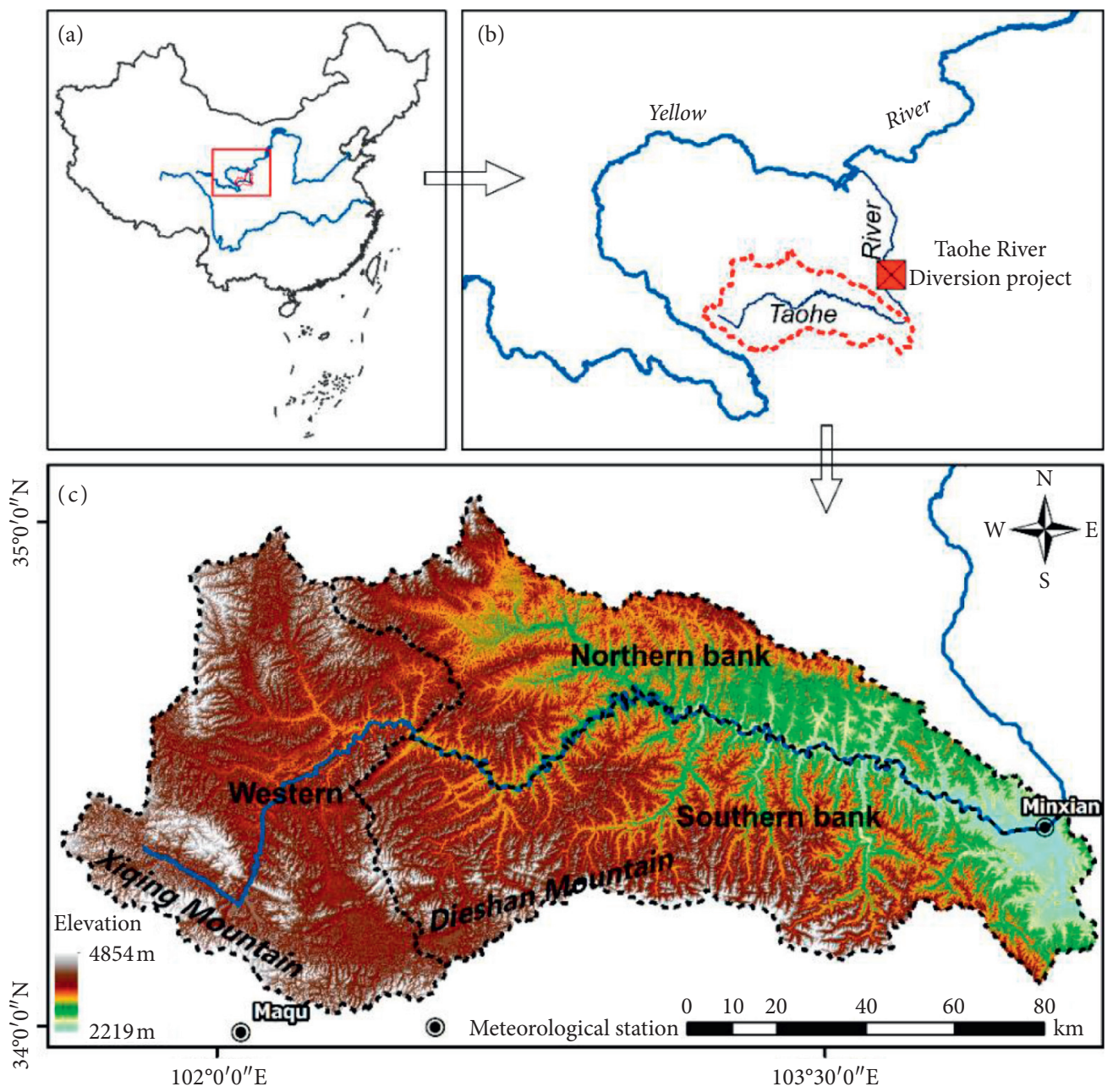

FIgURE 1: Location of the upper Taohe River basin and the divided three subzones: western zone, northern zone, and southern zone.

renewed in January 2019 during 2001-2018, which were temporally available at 8 -day products and spatially available at 500-meter pixel resolution. The MOD16 algorithm is based on the logic of Penman-Monteith equation which uses daily meteorological reanalysis data and 8-day remotely sensed vegetation property dynamics from MODIS as inputs [28]. Fourteen types of land coverage were included with corresponding land surface variables of fraction of absorbed photosynthetically active radiation (FPAR), leaf area index (LAI), and albedo or how much sunlight is reflected from the Earth at the top of the atmosphere under all-sky condition (both clear and cloudy situations) [28]. It includes evapotranspiration (ET), potential evapotranspiration (PET), latent heat flux (LE), potential latent heat flux (PLE), and quality control (ET_QC) variables. The data provide accurate precision of estimation which serves the requirement of this research.

In data-scarce regions, such as the upper Taohe River basin, where observations are sparse or unevenly distributed, satellite rainfall estimates provide essential, timely, and spatiotemporal information data. In this study, we used daily TRMM precipitation product (3B42V7) acquired from NASA's TRMM site to calculate the regional evapotranspiration by principle of water balance. For the accuracy of TRMM data in the upper Taohe River basin, the estimation results by Cheng et al. [29] suggested that TRMM data at monthly scale exhibited the best performance, which is close to the "truth value."

GLEAM evapotranspiration algorithm product was developed by Miralles et al, [30] and is available at http:// geoservices.falw.vu.nl. This algorithm uses precipitation, soil moisture, and vegetation water content as control conditions to calculate surface evapotranspiration and global potential evapotranspiration (PET) based on Priestley-Taylor formula. GLEAM includes all components of evapotranspiration (E): vegetation transpiration (Et), canopy interception evaporation (Ei), bare soil evaporation, snow sublimation evaporation, and water surface evaporation. The temporal and spatial resolutions of GLEAM are $1 \mathrm{~d}$ and $0.25 \times 0.25^{\circ}$, respectively. In this study, GLEAM data from 2001 to 2018 in upper Taohe River were used for comparison with MODIS MOD16 ET data.

2.2.2. Meteorological and Hydrological Data. The monthly and annual runoff data (in the period of 2001-2014) from Minxian gauging station were selected to calculate the 
regional evapotranspiration in the upper Taohe River basin, which were provided from Hydrology and Water Resources Bureau of Gansu Province. To explore the possible causes of ET in this basin from the perspective of climatic factors patterns, several daily meteorological data from typical stations during 2001-2018 in Maqu and Minxian stations were collected from China Meteorological Science Data Sharing Service Network (http://cdc.ma.gov.cn), including mean temperature, sunshine hours, atmospheric pressure, and wind speed.

2.2.3. Geographical Data. The digital elevation model (DEM) data used ASTER GDEM $30 \mathrm{~m}$ DEM version 1 obtained from http://www.gscloud.cn/sources. Based on DEM data of Taohe River basin, we extracted the upper Taohe River basin boundary. Given the potential impact of different land-use types on ET and PET, land-cover/use data from the years of 2000, 2005, 2010, and 2015 (from http:// www.resdc.cn/) were used to present changes of land use and evolution of ET in the upper Taohe River basin from 2001 to 2018. In order to match the spatial resolution to MOD16 data, land-use data were resampled as a gridded dataset at the same spatial resolution of $500 \mathrm{~m}$ and were masked by a boundary map of the study area. Since MODIS does not estimate ET over the water bodies [28], this study only analyzed the temporal and spatial variations of ET and PET over mainly 3 kinds of land use, followed by grass land, forest, and crop land.

\section{Methods}

3.1. Data Preprocessing. MODIS Reprojection Tool (MRT) was used to convert projection into longitude and latitude by taking WGS-8 as reference surface $[31,32]$, since MOD16 datasets are stored in an extension of HDF4 file format from NASA's Earth Observing System projects and cannot be read directly for users. Based on DEM data of the upper Taohe River basin, spatial and temporal average ET and PET data were generated through removing outlier data according to MODIS MOD16 ET product description file and ET_QC data.

3.2. Water Balance Method. Water balance method is one of the effective approaches in calculating actual evapotranspiration at a regional watershed, which has been widely used to estimate global evapotranspiration change, as well as crop and vegetation water demand [33]. It is a concrete manifestation of mass conservation principle in water circulation and also is the basic premise that the water cycle on the Earth can continue to progress [34]. Until now, water balance method is the most reliable approach to estimate ET in longtime series over regional watershed. According to principle of watershed water balance, observed runoff and satellite TRMM data are used to calculate annual and seasonal actual ET of the watershed (WBET).

The general water balance equation can be presented as

$$
\Delta S=P-R-\mathrm{ET},
$$

where $P$ and $R$ represent precipitation and total outflow including runoff of groundwater and rivers in the upper Taohe River basin; ET is calculated by water balance model; $\Delta S$ represents annual variations of soil moisture storage, groundwater, surface water, snow melt, and so on. For multiyear time series, changes in water storage are insignificant and usually stable. The ET of the watershed is taken as reference value of actual evapotranspiration.

3.3. Mann-Kendall Test. The nonparametric Mann-Kendall (M-K) test method is one of the effective methods recommended by the World Meteorological Organization, developed by Mann [35] and Kendall [36]; it has been widely used to analyze the significant long-term trends in different variables [35-37]. In this study, M-K test method was used to detect tendencies and abrupt points in ET and PET from 2001 to 2018.

For a sequence, $\left(x_{1}, x_{2}, x_{3}, \cdots, x_{n}\right)$ are the time series, and the results are recorded as $\operatorname{sgn}\left(x_{j}-x_{k}\right)$ :

$$
\operatorname{sgn}\left(x_{j}-x_{k}\right)= \begin{cases}1, & \left(x_{j}-x_{k}>0\right), \\ 0, & \left(x_{j}-x_{k}=0\right), \\ -1, & \left(x_{j}-x_{k}<0\right),\end{cases}
$$

where $x_{j}$ and $x_{k}$ are the series of evapotranspiration, $n$ is the length of time series; $k=1,2, \cdots, n-1, j=2,3, \cdots, n$.

The Mann-Kendall statistic is calculated as

$$
S=\sum_{k=1}^{n-1} R_{i} \sum_{j=k+1}^{n} \operatorname{sgn}\left(x_{j}-x_{k}\right) \text {. }
$$

The test statistic $Z$ is

$$
Z= \begin{cases}\frac{S+1}{\sqrt{\operatorname{VAR}(S)},} & (S>0), \\ 0, & (S=0), \\ \frac{S-1}{\sqrt{\operatorname{VAR}(S)},} & (S<0),\end{cases}
$$

where

$$
\operatorname{VAR}(S)=\frac{n(n-1)(2 n+5)}{18}
$$

In this equation, when $Z$ is $-1.96 \leq Z \leq 1.96$, the null hypothesis is accepted, indicating that there is no obvious trend in samples. The trend is significant at the $95 \%$ confidence level if $|Z|>1.96$ and at the $99 \%$ confidence level if $|Z|>2.58$. A positive $Z$ indicates that the sequence has a rising trend, while a negative $Z$ reflects a declining trend [36].

In addition, the nonparametric Mann-Kendall test method was also applied for changing points. For the time 
series $x$ with $n$ sample, an order column $S_{k}$ was built as follows:

$$
S_{k}=\sum_{i=1}^{k} r_{i}(k=1,2, \cdots, n),
$$

where

$$
r_{i}= \begin{cases}1, & x_{i}>x_{j}, \\ 0, & x_{i}<x_{j}, \\ (j=1,2, \cdots, i) . & \end{cases}
$$

$S_{k}$ is the accumulated value when the number in the $i$ moment is greater than the value of $j$.

Statistics of the sequence were defined under the assumption of random independent time series:

$$
\mathrm{UF}_{k}=\frac{\left[S_{k}-E\left(S_{k}\right)\right]}{\sqrt{\operatorname{VAR}\left(S_{k}\right)}} \quad(k=1,2, \cdots, n),
$$

where $\mathrm{UF}_{1}=0 ; E\left(S_{k}\right)$ and $\operatorname{Var}\left(S_{k}\right)$ represent the values of average and square deviation, respectively:

$$
\begin{aligned}
E\left(S_{k}\right) & =\frac{n(n-1)}{4}, \\
\operatorname{VAR}\left(S_{k}\right) & =\frac{n(n-1)(2 n+5)}{72} .
\end{aligned}
$$

In the case of $\mathrm{UF}_{i}>U_{\alpha}$, in which $U_{0.05}= \pm 1.96$ and $U_{0.01}= \pm 2.57$, it is indicated that the sequence trend line is significant. When $\mathrm{UF}_{i}$ is positive, it indicates that the sequence is on upward trend; otherwise, it shows a downward trend, and the larger the absolute value is, the more significant the change trend of the sequence is [36].

3.4. Sen's Slope Method. To analyze the trend of ET and PET at grid scale, we used robust estimator for the amplitude of trend slopes as proposed by Sen in 1968:

$$
\operatorname{Sen}_{i j}=\operatorname{MEDIAN} \frac{\left(X_{j}-X_{i}\right)}{(j-i)} \quad(1 \leq i<j \leq n) .
$$

For a sequence, $x_{1}, x_{2}, x_{3}, \cdots, x_{i}, x_{j}, \cdots, x_{n}$ are the time series; $\operatorname{Sen}_{i j}$ is the monotonic increase or decrease rate of long-time data series. Final slope of Sen is the median value, which is determined by the parity of total number.

$$
\begin{aligned}
N & =n(n-1), \\
\text { Sen } & = \begin{cases}\operatorname{Sen}_{k+1}, & N=2 k+1, \\
\frac{\operatorname{Sen}_{k}+\operatorname{Sen}_{k+1}}{2}, & N=2 k,\end{cases}
\end{aligned}
$$

where $k$ is an integer related to the sequence length. If Sen value is positive, the series monotonically increases; otherwise, if Sen value is negative, the series monotonically decreases [38].

This method is constructed statistics' test at the change rate of different lengths based on a certain level of significance, obtaining numerical ranges of values. Sen's slope trend test can eliminate the impact of missing data or anomalous trends by using the median of slopes series as the judgmental foundation. In this study, we selected Sen's slope method to detect and characterize trends of ET and PET in the upper Taohe River basin.

3.5. Evaluation Method. To assess the consistency between MOD16 ET data and WBET, serval comparative variables were used, such as coefficient of determination $\left(R^{2}\right)$, root mean square error (RMSE), and BIAS. The calculation formulas are as follows:

$$
\begin{aligned}
R^{2} & =\frac{\sum_{i=1}^{n}\left(\mathrm{WBET}_{i}-\overline{\mathrm{WBET}}\right)\left(\mathrm{MET}_{i}-\overline{\mathrm{MET}}\right)}{\sqrt{\sum_{i=1}^{n}\left(\mathrm{WBET}_{i}-\overline{\mathrm{WBET}}\right)^{2}} \sqrt{\sum_{i=1}^{n}\left(\mathrm{MET}_{i}-\overline{\mathrm{MET}}\right)^{2}}}, \\
\text { RMSE } & =\sqrt{\frac{1}{n} \sum_{i=1}^{n}\left(\mathrm{WBET}_{i}-\mathrm{MET}_{\mathrm{i}}\right)^{2}}, \\
\text { BIAS } & =\frac{\sum_{i=1}^{n}\left(\mathrm{WBET}_{i}-\mathrm{MET}_{i}\right)}{\sum_{i=1}^{n} \mathrm{MET}_{i}} \times 100 \%,
\end{aligned}
$$

where WBET is the total ET calculated by water balance model; MET represents MOD16 ET estimations; and N is the number of time series. When BIAS and RMSE values are close to zero, the MOD16 ET estimations agree well with WBET values, indicating that MODIS data is deemed accurate.

\section{Results}

4.1. Evaluations of MOD16 ET Data. There are scarce meteorological stations of evapotranspiration measurement, which has brought about great inconvenience to evaluate MOD16 ET products using in situ ET observations from stations. Therefore, observed runoff and satellite TRMM data are used to calculate annual and seasonal actual ET of the watershed (WBET) according to watershed water balance principle. From Figure 2, it was easily seen that water amount remained relatively balanced and with a minute budget of $-7 \mathrm{~mm}$. Average values of MODIS-estimated ET values and WBET were $448.02 \mathrm{~mm}$ and $455.83 \mathrm{~mm}$, respectively. MODIS ET data was evaluated at seasonal scale using WBET values from 2001 to 2014, as shown in Figure 3. The scatter results showed consistent association between MODIS-estimated ET values and WBET during 2001-2014. Correlation coefficient $R^{2}$ between WBET and MOD16 ET was 0.85, and RMSE and BIAS were $64.62 \mathrm{~mm}$ and $2.01 \mathrm{~mm}$, respectively. These reasonable statistic indices demonstrated that MODIS data well captured the seasonal variability of WBET and had a good systematic consistence. This study also used the pan evapotranspiration from 2001 to 2013 at Luqu station to estimate MOD16 PET data, as shown in Figure 4 . The annual results showed high consistency between pan evapotranspiration and PET estimated by MOD16. In addition, pan evapotranspiration and PET estimated by MOD16 showed good agreement in spring, autumn, and 


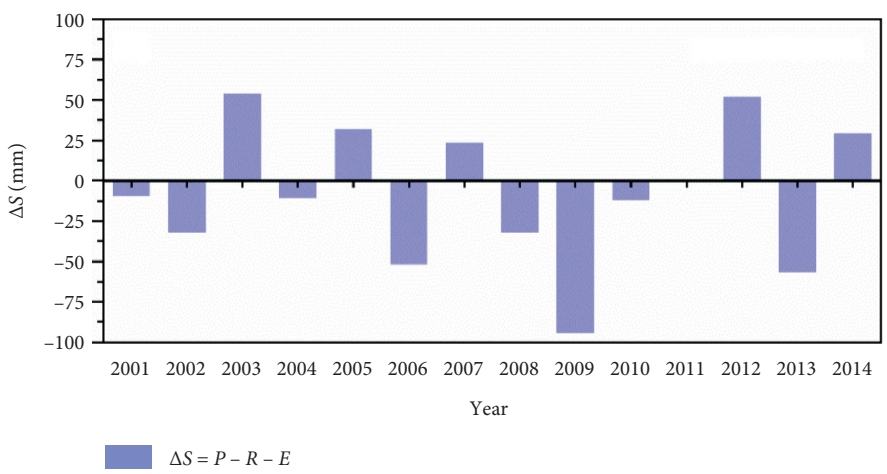

(a)

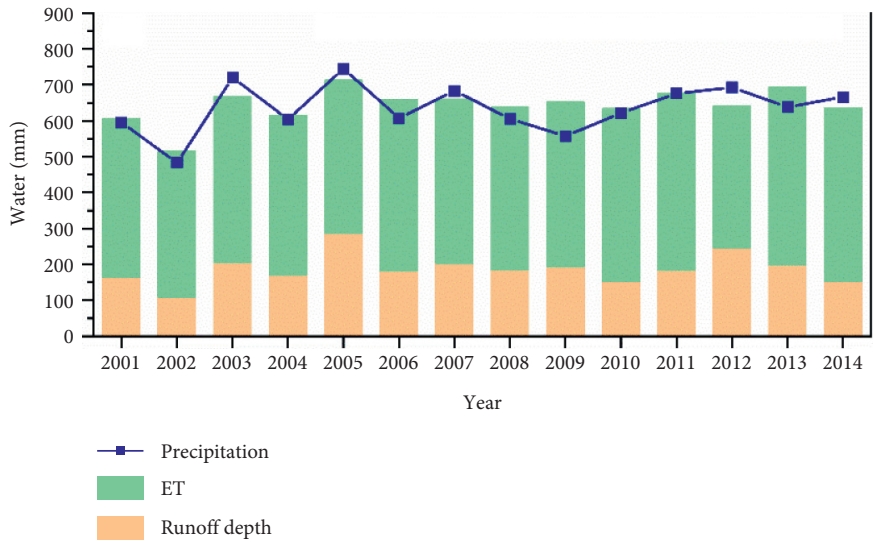

(b)

FIgURE 2: Water budget changes and correspondence between ET and precipitation by TRMM and runoff depth in the upper Taohe River basin during 2001-2014.

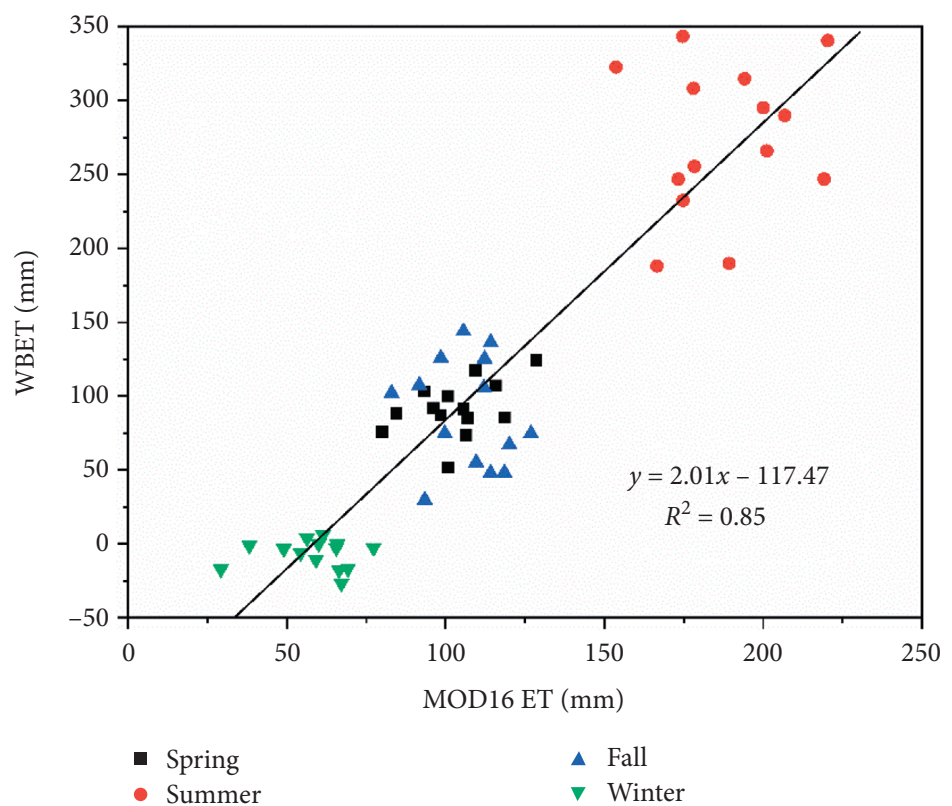

FIGURE 3: Scatter between evapotranspiration obtained by water balance (WBET) and MOD16 ET data at seasonal scale.

winter but not in summer. Overall, MOD16-estimated ET data had relatively high quality in upper Taohe River basin, and it can be used to further explore the investigation of ET and PET variations and water resources managements furtherly.

\subsection{Temporal Variations of Annual ET and PET}

4.2.1. Annual and Seasonal Changes in ET. Average ET variations in study region and three subzones during 


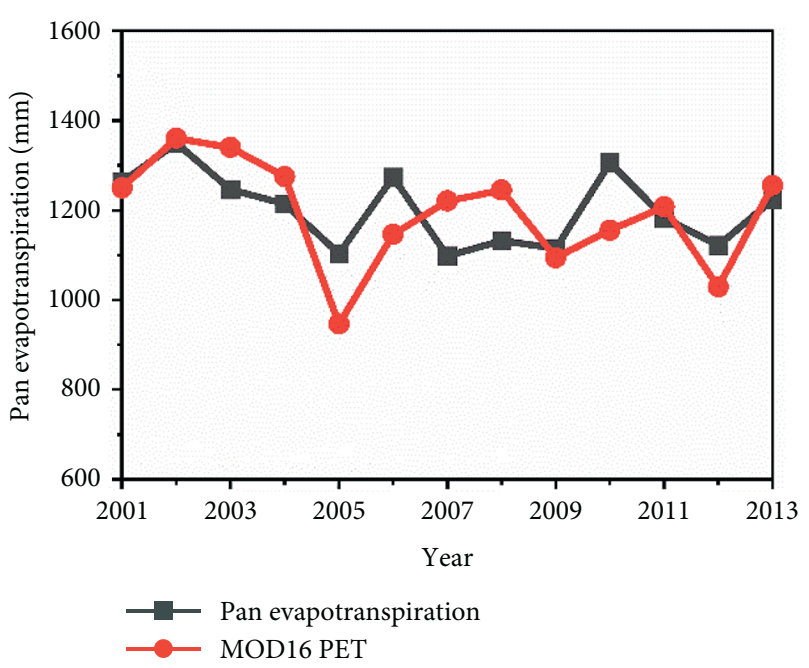

(a)

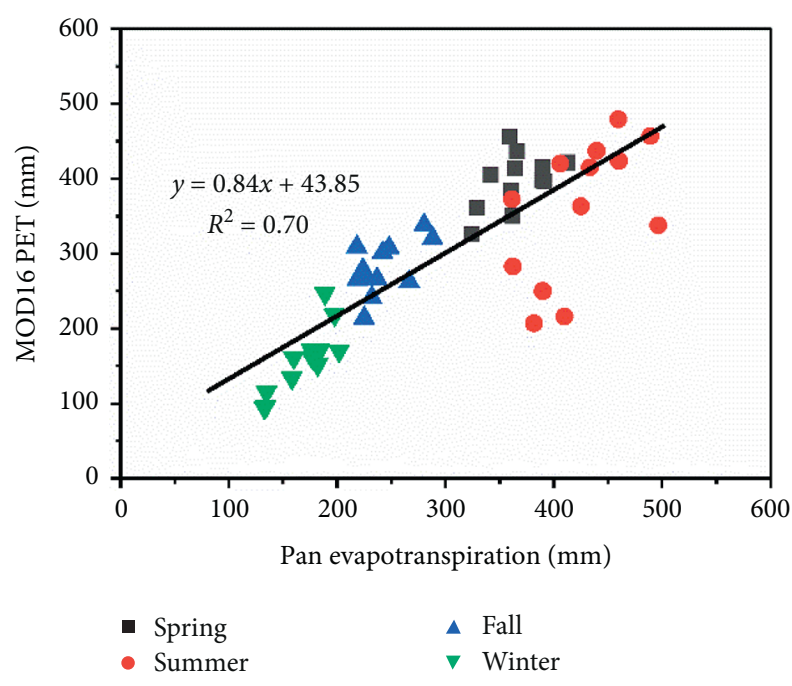

(b)

FIgURE 4: Consistency analysis of MOD16 PET data and pan evapotranspiration.

2001-2018 were shown in Figure 5. The multiyear mean ET was $464.2 \mathrm{~mm}$, which was close to the average value of whole China $(442.6 \mathrm{~mm})$ [7]. The lowest and highest ET were $395.3 \mathrm{~mm}$ and $546.4 \mathrm{~mm}$, occurring in 2012 and 2016, respectively. There was a significant increasing ET trend with a rate of $3.48 \mathrm{~mm} / \mathrm{a}$, which is much higher than that in China and the source of Yellow River basin, with $1.23 \mathrm{~mm} / \mathrm{a}$ and $0.44 \mathrm{~mm} / \mathrm{a}$, respectively $[7,32]$. Compared with the period of 2001-2008, mean ET in the period of 2009-2018 increased by $7.2 \%$ from $446.35 \mathrm{~mm}$ to $478.57 \mathrm{~mm}$.

At the seasonal scale, ET was highest in summer and lowest in winter, with mean values of $190.05 \mathrm{~mm}$ and $57.22 \mathrm{~mm}$, respectively. The seasonal ET changes shown in Figure 6(b) and Table 1 indicated that ET increased significantly in spring by a rate of 3.11 and insign ificantly in other seasons. At the regional scale, obvious difference of ET distribution over subregions is shown in Figure 7(b), since water resources are unevenly distributed in time and space. It was easily seen that ET was highest in the northern zone and lowest in the western zone. Also, three subzones had different increasing rates shown in Table 1. ET increased most significantly in the northern zone $(Z=3.03)$, especially in spring $(Z=3.11)$, which indicated that ET increase in the northern zone contributed mostly for whole region.

4.2.2. Annual and Seasonal Changes in PET. The temporal variations of PET can be depicted in Figure 5 over the upper Taohe River basin from 2001 to 2018. PET was much higher than mean ET because of difference in available water amount driven by climatic factors and soil and vegetation characteristics [7]. Compared with average PET calculated by Penman-Monteith formula of China (941.5 mm), the multiyear mean PET based on MODIS data in this region was $1192.2 \mathrm{~mm}$, which was higher than that in other regions of China [6]. Average PET was lowest in $2012(976.2 \mathrm{~mm})$ and highest in 2002 (1326.9 mm). From Figure 5, a decreasing trend was presented in PET at a rate of
$-8.18 \mathrm{~mm} / \mathrm{a}$. All the negative $\mathrm{M}-\mathrm{K}$ results of PET were shown in Table 1 and passed the 95\% significance level, which identified the significant downward trend of PET.

The seasonal change pattern is shown in Figure 6(a). Annual PET was higher in summer and spring and lower in winter and fall, respectively. There was a remarkable decrease in fall $(Z=-2.12)$ and an insignificant one in spring and winter $(Z=-0.53$ and -0.54$)$. At the regional scale (Figure 7(a)), annual PET was highest in the northern zone $(1222.11 \mathrm{~mm})$ and lowest in the western zone $(1180.84 \mathrm{~mm})$. Additionally, annual PET decreased remarkably $(Z=-2.12)$ in the northern zone and slightly in the western zone, which illustrated that PET changes in the northern zone were more significant than those in other regions and contributed mostly to the whole basin.

\subsection{Spatial Distribution and Changes in ET and PET}

4.3.1. Spatial Trend in ET. Spatial distributions of ET during 2001-2018 in upper Taohe River basin are presented in Figure 8(a). It can be easily seen that ET was highest from $500 \mathrm{~mm}$ to $580 \mathrm{~mm}$ and concentrated mostly in the western and northern zone. Annal ET ranged from $400 \mathrm{~mm}$ to $500 \mathrm{~mm}$ in other regions except some margin mountainous regions and water surface, where ET estimations were not inverted by satellite. To evaluate spatial heterogeneity and variability of ET quantitatively, this study analyzed the Sen slopes by equalizing the rate of each year from 2001 to 2018 on a grid scale. The spatial trends and significances of ET changes were illustrated in Figure 8(b), and several levels were regionally aggregated in the upper Taohe River basin. Results showed that both significant increasing and decreasing tendencies ranging from $-9 \mathrm{~mm} / \mathrm{a}$ to $16 \mathrm{~mm} / \mathrm{a}$ were found in the study region. On the whole, the increasing trend was presented in most regions and the maximum rate was found in the northeast zone with more than $10 \mathrm{~mm} / \mathrm{a}$. 


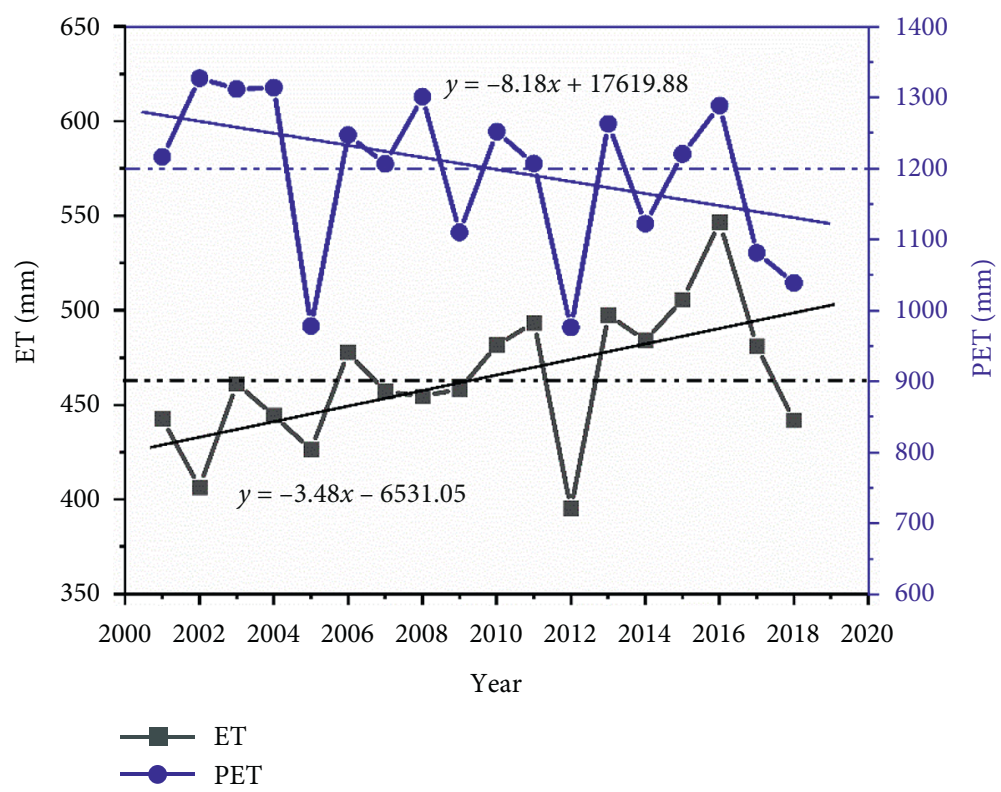

FIgUre 5: Temporal changes of annual ET and PET in the upper Taohe River basin during 2001-2018.

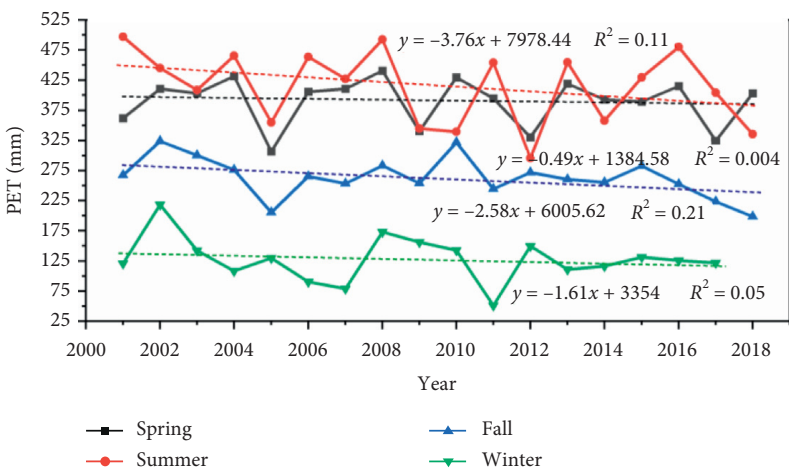

(a)

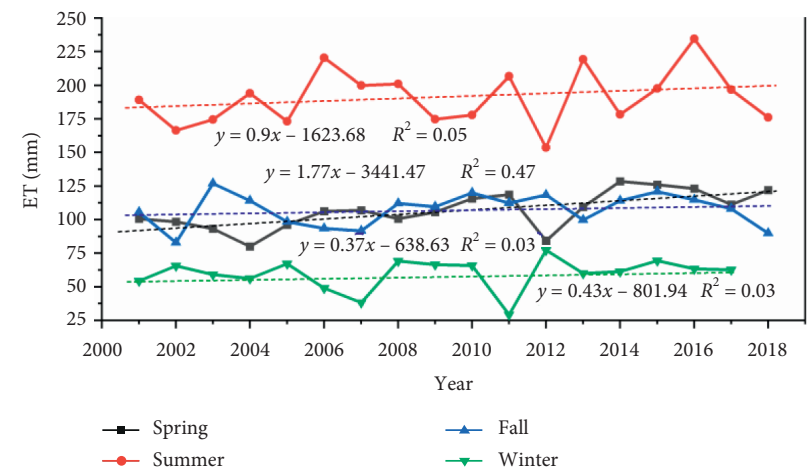

(b)

Figure 6: The seasonal changes of PET (a) and ET (b) in the upper Taohe River basin during 2001-2018.

TABLE 1: Results of M-K test for annual and seasonal ET and PET in whole basin and subzones during 2001-2018 (slope unit: mm/year).

\begin{tabular}{cccccccccccc}
\hline & \multirow{2}{*}{ Region } & \multicolumn{2}{c}{ Yearly } & \multicolumn{2}{c}{ Spring } & \multicolumn{2}{c}{ Summer } & \multicolumn{2}{c}{ Fall } & \multicolumn{2}{c}{ Winter } \\
& & $Z$ & Slope & $Z$ & Slope & $Z$ & Slope & $Z$ & Slope & $Z$ & Slope \\
\hline \multirow{4}{*}{ ET } & Basin & 2.35 & 3.97 & 3.11 & 1.79 & 1.14 & 0.94 & 0.68 & 0.44 & 0.87 \\
& Western & 1.97 & 3.42 & 2.42 & 1.61 & 0.53 & 0.53 & 0.76 & 0.36 & 1.11 & 0.48 \\
& Northern & 3.03 & 4.49 & 3.18 & 1.96 & 1.74 & 1.75 & 0.45 & 0.32 & 0.29 & 0.12 \\
& Southern & 2.20 & 4.04 & 3.18 & 1.83 & 0.61 & 0.73 & 0.45 & 0.45 & 0.87 & 0.40 \\
\hline \multirow{4}{*}{ PET } & Basin & -1.74 & -8.45 & -0.53 & -1.08 & -1.44 & -3.57 & -2.12 & -3.45 & -0.54 & -1.49 \\
& Western & -1.29 & -9.70 & -0.68 & -1.04 & -0.98 & -2.76 & -2.05 & -3.14 & -0.70 & -0.98 \\
& Northern & -2.12 & -9.10 & -0.30 & -0.43 & -1.36 & -4.00 & -2.12 & -3.45 & -0.87 & -1.56 \\
& Southern & -1.67 & -9.22 & -0.30 & -0.84 & -1.36 & -4.00 & -2.05 & -3.46 & -0.70 & -1.30 \\
\hline
\end{tabular}

At the seasonal scale, ET distributions in different seasons were demonstrated in Figure 9. In spring, ET was almost ranging from 100 to $130 \mathrm{~mm}$ except in mountainous regions and water surface, which was consistent with the annual ET distribution. As spring begins, the temperature increases gradually with solar radiation intensified, which dominated the changes of ET. In summer, remarkable difference between the west and the east can be easily found. 


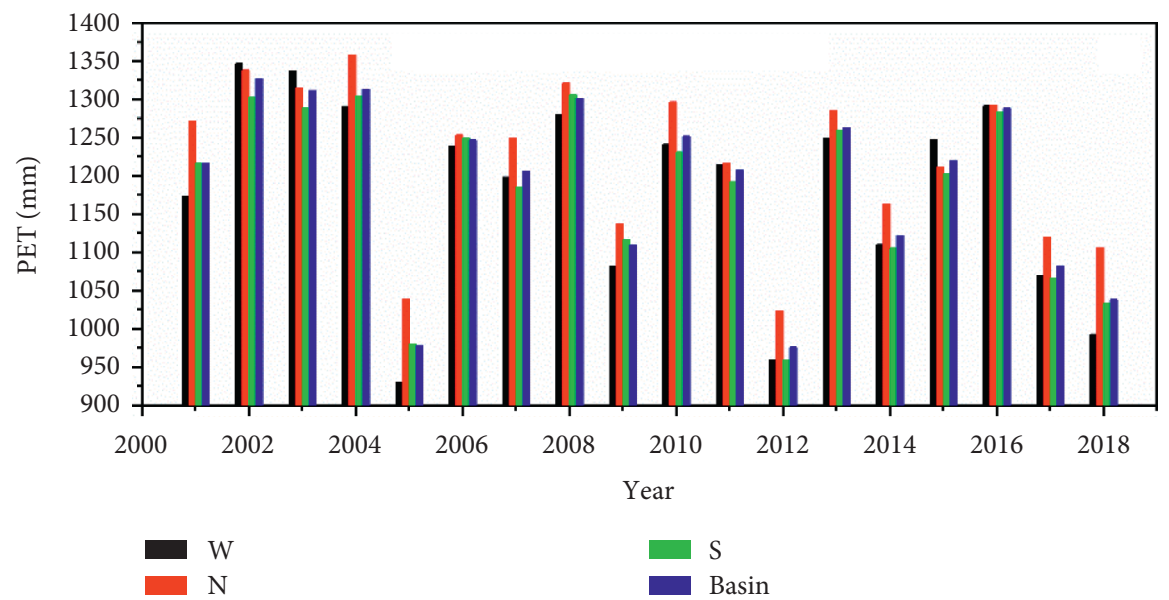

(a)

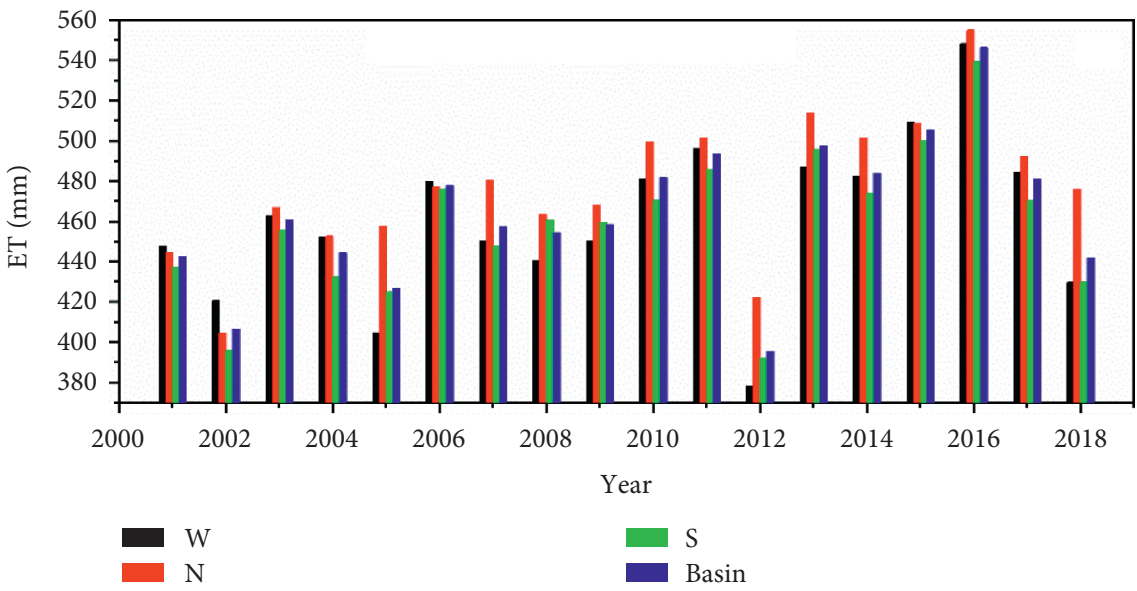

(b)

FIgURE 7: Temporal changes of annual PET (a) and ET (b) in whole basin and three subzones from 2001 to 2018.

ET in the east was much higher than that in the west, which may be caused by the high temperature, abundant precipitation, and strong solar radiation. In summer, vegetation grew vigorously and the increased soil water storage was consumed by intensive evapotranspiration [32]. In fall, most of the regions were characterized by uniformity distribution ranging from $100 \mathrm{~mm}$ to $110 \mathrm{~mm}$. Also annual ET was lower in winter, which may be attributed to low temperature with weak solar radiation, and vegetation was withering in alpine regions [32]. Overall, ET of the northern region in summer was the strongest and made the greatest contribution to the variations. In addition, the differences between the east and the west reflected the relatively instable water-heat balance status among subregions, which may cause some extreme drought in northern and central regions nearby Loess Plateau.

4.3.2. Spatial Trend in PET. Spatial distributions of PET during 2001-2018 in upper Taohe River basin are presented in Figure 8(c). It can be easily seen that most regions were characterized by uniformity distribution ranging from
$1000 \mathrm{~mm}$ to $1300 \mathrm{~mm}$, and the highest PET concentrated mostly in the northern zone. On the whole, the significant decreasing trends were presented (Figure $8(\mathrm{~d})$ ) in most regions ranging from $-40 \mathrm{~mm} / \mathrm{a}$ to $-10 \mathrm{~mm} / \mathrm{a}$, except some increasing trends occurring in margin western and eastern regions.

At the seasonal scale, PET distributions shown in Figure 10 were consistent. In spring and summer, annual PET was high, ranging from 350 to $500 \mathrm{~mm}$, and there were remarkable differences between the western and eastern zones; and PET in the east was much higher than that in the west. Overall, PET in spring and summer was the stronger and made the biggest contribution to the variations. In fall and winter, most of the regions were characterized by uniformity distribution with lower PET ranging from $150 \mathrm{~mm}$ to $300 \mathrm{~mm}$.

\subsection{Variations of ET and PET under the Different Land Use}

4.4.1. Variations of Land Use. Land-use change is the direct result of regional environmental change and human 

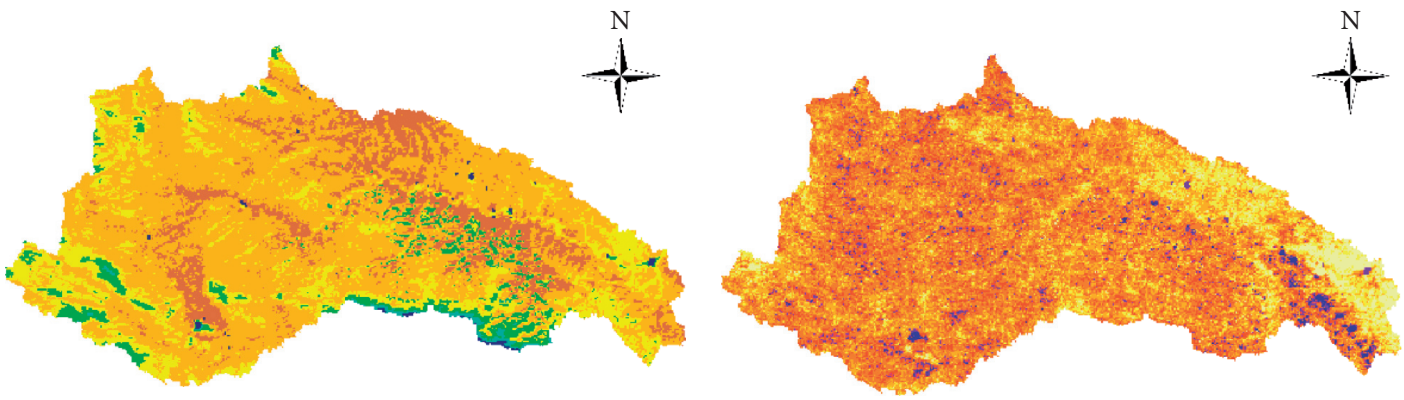

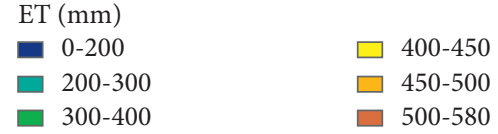

(a)

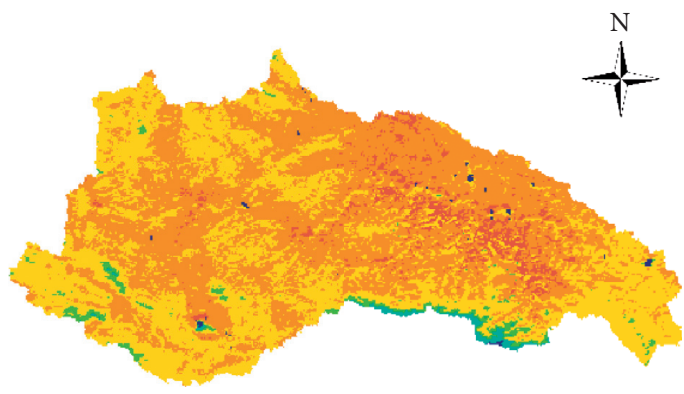

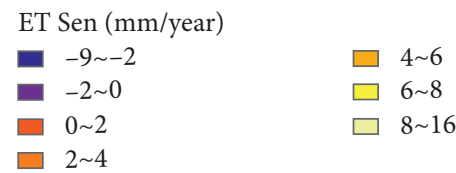

(b)

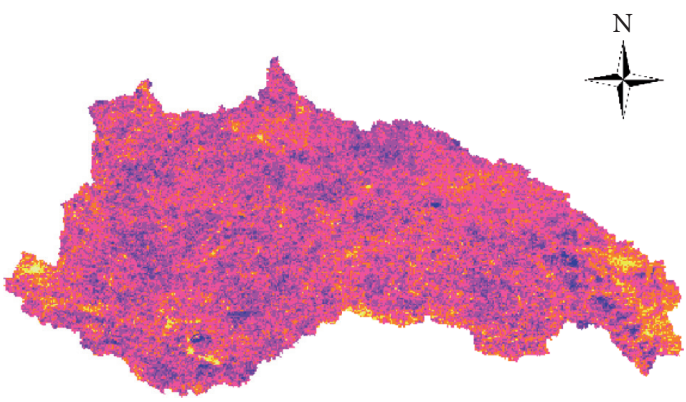

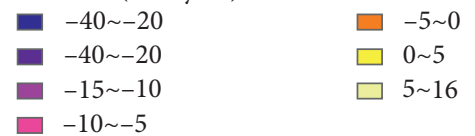

(d)

(c)

FIgURE 8: Spatial distributions based on MOD16 data and change rates of ET (a and b) and PET (c and d) over the upper Taohe River basin from 2001 to 2018 .

activities, which can affect regional hydrologic process and water balance [39-41]. Therefore, it is important to explore variations of ET and PET in land use. The proportion and changes of land use during 2001-2018 in upper Taohe River basin are shown in Figure 11 and Table 2. It can be easily seen that grass land was the major land use accounting for over $60 \%$ of the whole region, which mainly distributed in Gannan Plateau. In addition, forest was another main type followed by grass land with the percentage of about $26 \%$, which was mostly distributed in mountainous areas over the west and south margins. Meanwhile cropland was less, accounting for about $6.7 \%$ and mainly distributed in the eastern zone nearby Loess Plateau. These three main landuse types accounted for more than $95 \%$ of the total area, and other types including water, residents, and unused land accounted for less than 5\%. Therefore, three main kinds of land-use types, grass land, forest, and cropland, were investigated to represent changes of ET and PET in this research.

From Table 2, the slight changes of land use in upper Taohe River basin indicated that this region kept stable natural situation with fewer human activities. These good effects also were attested to the success of Chinese Government that began implementing the Grain-for-Green (GFG) Program in 1999 to alleviate severe land degradation in Loess Plateau, which mandated converting steeply sloping croplands to forestlands or grasslands as well as afforestation [42]. For example, Li et al. [24] found that NDVI and vegetation coverage had an obvious growth trend with the implementation of ecological engineering and vegetation conditions in Taohe River area.

4.4.2. Variations of ET and PET under the Different Land Use. Land-use changes might have a certain impact on ET and PET variations. Generally, ET in some land-use types with vegetation was higher than those without vegetation cover [32]. Annual variation processes of average ET and PET in different land use in upper Taohe River basin are shown in Table 2 and Figure 12. Results showed that ET experienced an increasing trend in different land use from 2001 to 2018, and the increments of ET in cropland, grass, and forest were 

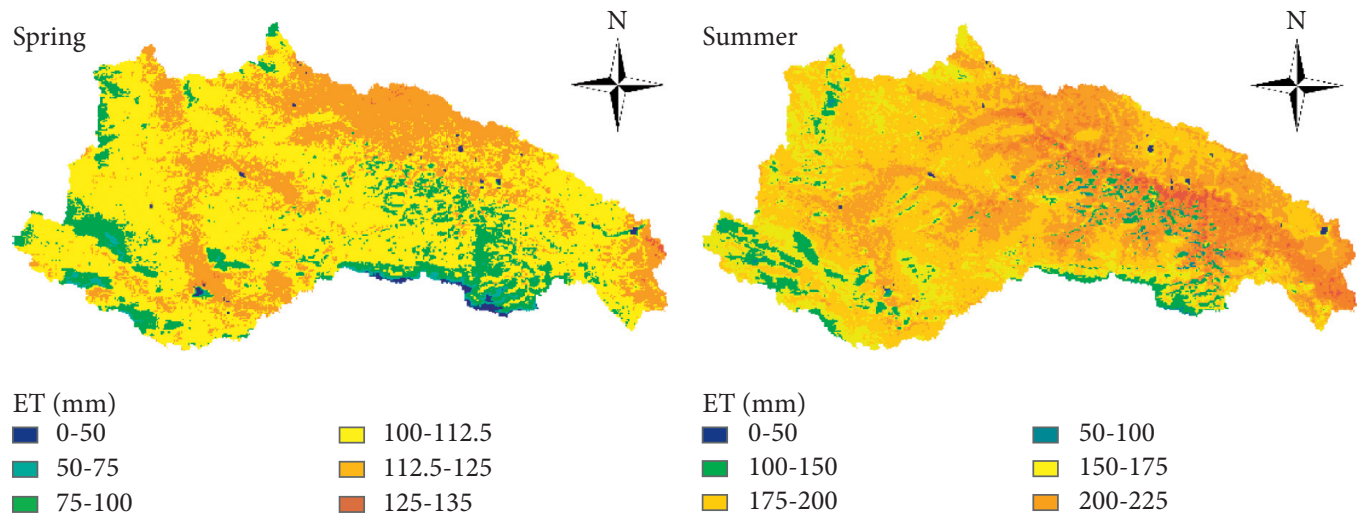

$$
\begin{aligned}
& \square 100-112.5 \\
& \square 112.5-125 \\
& \square 125-135
\end{aligned}
$$

(a)

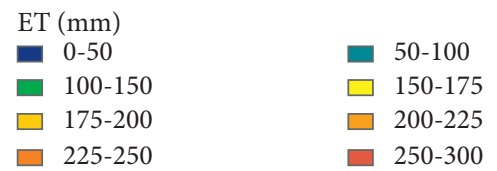

(b)
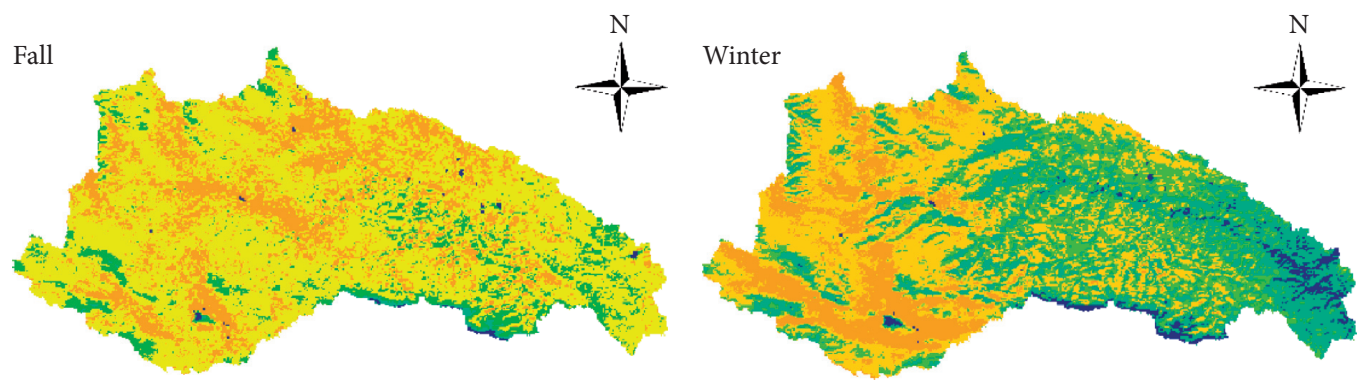

$\mathrm{ET}(\mathrm{mm})$

$\begin{array}{ll} & 0-50 \\ & 50-75 \\ & 75-100\end{array}$

$\square \quad 100-112.5$

ET (mm)

- $0-25$

- 25-50

$\square \quad 62.5-75$

- 50-62.5

(c)

(d)

FIgURE 9: Spatial distributions of seasonal ET during 2001-2018 in the upper Taohe River basin.
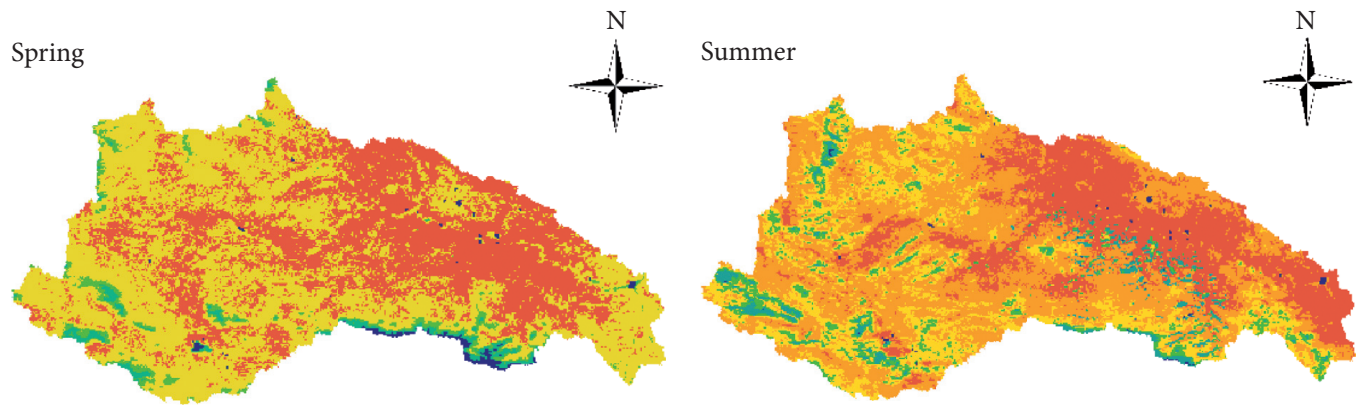

PET (mm)

- $\begin{array}{ll}0-200 \\ 200-300 \\ 300-350\end{array}$

$\square 350-400$

- 400-450

(a)

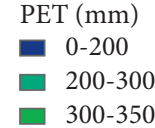

- 300-350

Figure 10: Continued. 

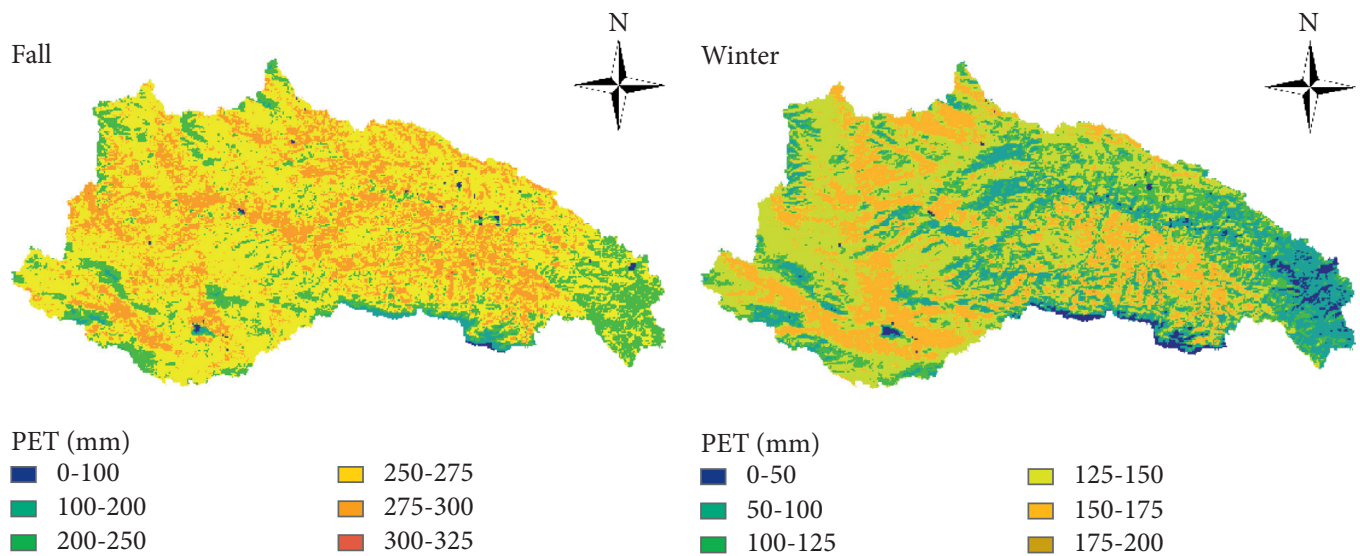

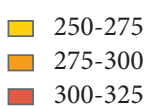

(c)

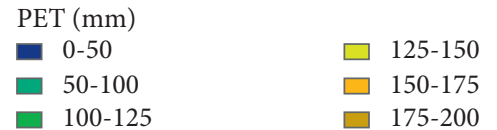

(d)

FIgURE 10: Spatial distributions of seasonal PET during 2001-2018 in the upper Taohe River basin.

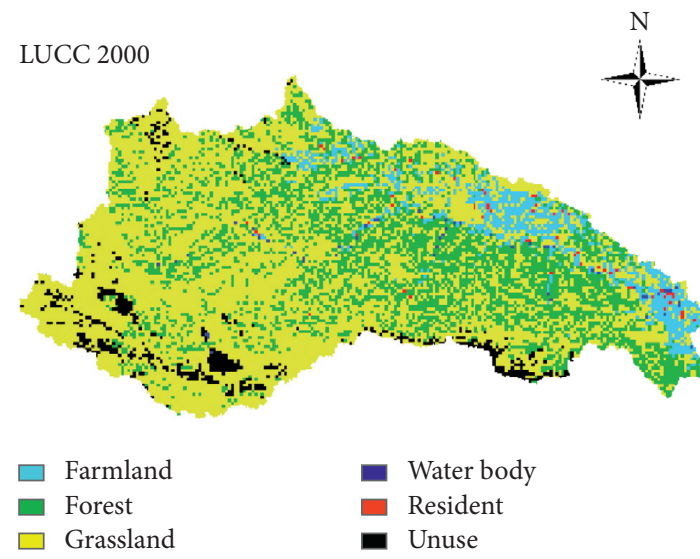

(a)

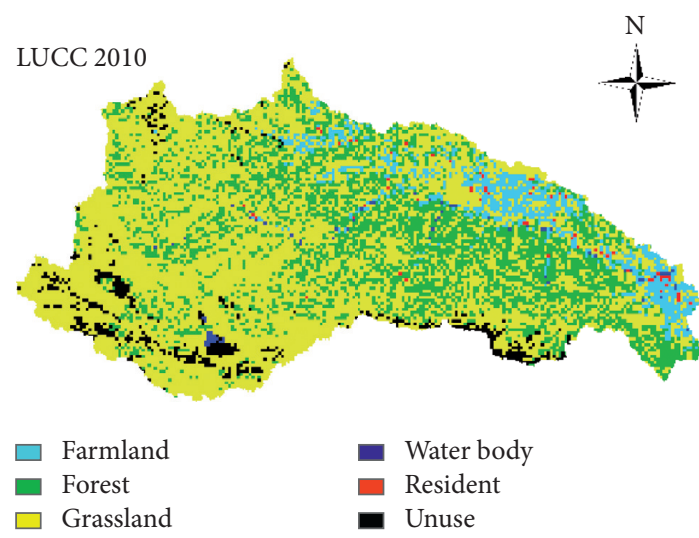

(c)

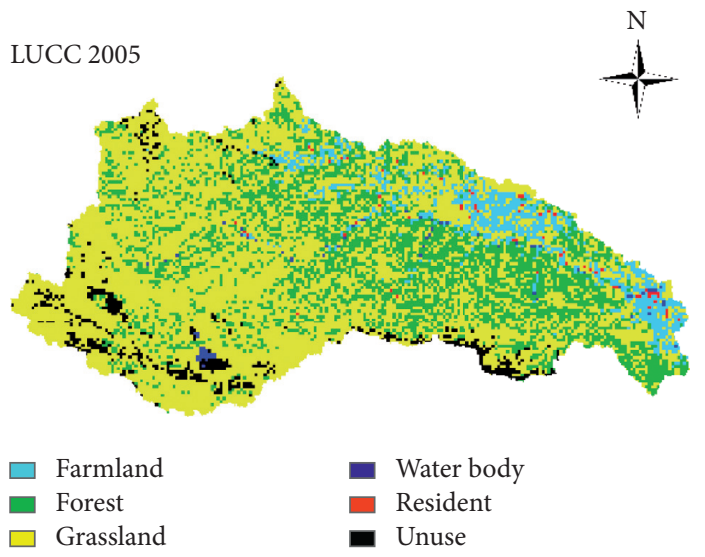

(b)

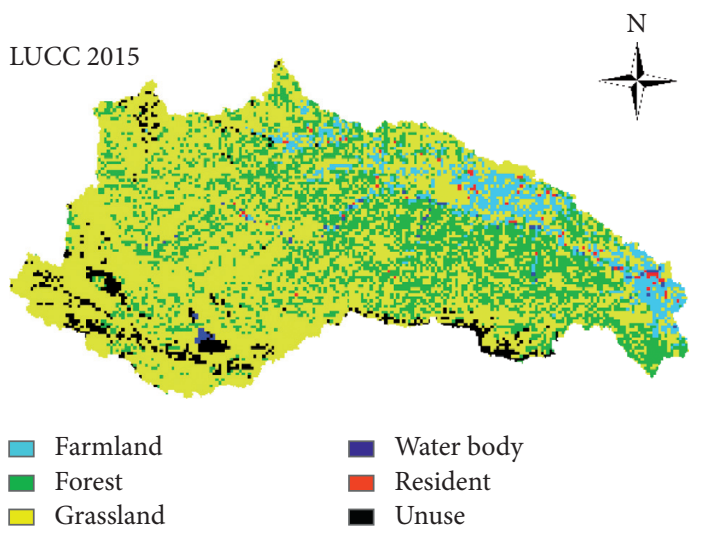

(d)

FIgURE 11: Spatial distributions of land use from the dataset of years 2000, 2005, 2010, and 2015 in the upper Taohe River basin.

$91.27 \mathrm{~mm}, 51.63 \mathrm{~mm}$, and $53.27 \mathrm{~mm}$, which were increased by the rates of $21 \%, 11.61 \%$, and $12.03 \%$, respectively. Annual ET rise in cropland was significant mainly due to the change of water consumption associated with crop rotation in the cultivated areas. On the contrary, PET experienced a decreasing trend in different land use from 2001 to 2018. PET reductions in cropland, grass, and forest were $106.24 \mathrm{~mm}, 141.03 \mathrm{~mm}$, and $135.85 \mathrm{~mm}$, which were decreased by the rates of $8.24 \%, 10.75 \%$, and $10.47 \%$, respectively. PET changes in cropland were insignificantly 
TABLe 2: Distributions of ET and PET in different types of land use from 2001 to 2018.

\begin{tabular}{|c|c|c|c|c|c|c|c|c|c|c|c|c|}
\hline & \multicolumn{3}{|c|}{$2001-2004$} & \multicolumn{3}{|c|}{ 2005-2009 } & \multicolumn{3}{|c|}{ 2010-2014 } & \multicolumn{3}{|c|}{ 2015-2018 } \\
\hline & $\begin{array}{c}\mathrm{ET} \\
(\mathrm{mm})\end{array}$ & $\begin{array}{l}\text { PET } \\
(\mathrm{mm})\end{array}$ & $\begin{array}{c}\text { Area } \\
(\%)\end{array}$ & $\begin{array}{c}\mathrm{ET} \\
(\mathrm{mm})\end{array}$ & $\begin{array}{l}\text { PET } \\
(\mathrm{mm})\end{array}$ & $\begin{array}{c}\text { Area } \\
(\%)\end{array}$ & $\begin{array}{c}\mathrm{ET} \\
(\mathrm{mm})\end{array}$ & $\begin{array}{l}\text { PET } \\
(\mathrm{mm})\end{array}$ & $\begin{array}{c}\text { Area } \\
(\%)\end{array}$ & $\begin{array}{c}\mathrm{ET} \\
(\mathrm{mm})\end{array}$ & $\begin{array}{l}\text { PET } \\
(\mathrm{mm})\end{array}$ & $\begin{array}{c}\text { Area } \\
(\%)\end{array}$ \\
\hline Cropland & 415.69 & 1289.74 & 6.97 & 463.48 & 1194.24 & 6.79 & 488.15 & 1190.62 & 6.75 & 506.96 & 1183.50 & 6.68 \\
\hline Forest & 444.60 & 1310.81 & 26.88 & 463.67 & 1190.51 & 26.87 & 472.23 & 1173.83 & 26.86 & 496.23 & 1169.78 & 26.86 \\
\hline Grass & 442.94 & 1296.59 & 61.52 & 455.56 & 1169.19 & 61.70 & 472.42 & 1168.10 & 61.74 & 496.21 & 1160.76 & 61.71 \\
\hline $\begin{array}{l}\text { Unused } \\
\text { land }\end{array}$ & 382.11 & 1122.63 & 3.85 & 378.83 & 982.23 & 3.71 & 406.27 & 1012.06 & 3.73 & 424.80 & 994.05 & 3.74 \\
\hline Water body & - & - & 0.37 & - & - & 0.51 & - & - & 0.50 & - & - & 0.50 \\
\hline $\begin{array}{l}\text { Resident } \\
\text { area }\end{array}$ & - & - & 0.41 & - & - & 0.42 & - & - & 0.42 & - & - & 0.50 \\
\hline
\end{tabular}

attributed to the good effect of Chinese Government implementing the Grain-for-Green (GFG) Program. In summary, insignificant changes of land use and coverage had some contributions to variations of ET and PET.

\section{Discussions}

5.1. Comparison between MOD16 ET Data and GLEAM Data. In order to improve the credibility of MOD16 ET data, this study attempts to make a comparison between MOD16 ET data and GLEAM data. Results from Figure 13 showed that the actual evapotranspiration $(E)$ based on GLEAM varied from $480 \mathrm{~mm}$ to $580 \mathrm{~mm}$ from 2001 to 2018 in upper Taohe River basin. The regression analysis results showed that the actual regional evapotranspiration $(E)$ fluctuated and increased with an increasing rate of $0.50 \mathrm{~mm} / \mathrm{a}$. The vegetation evapotranspiration (Et) based on GLEAM varied from $420 \mathrm{~mm}$ to $520 \mathrm{~mm}$ from 2001 to 2018 , which is similar to the multiyear average of MOD16 ET.

\subsection{The Impacts of Climatic Factors on the Changes of ET and} PET. According to IPCC report, global temperature has increased by approximately $0.74^{\circ} \mathrm{C}$ on average in the past 100 years and would continue to increase by $1-5^{\circ} \mathrm{C}$ in China by the end of the 21 st century [43]. As the significant feature of climate change, spatial and temporal characteristics of ET and PET need to be analyzed furtherly and widely. Therefore, main meteorological variables (average temperature, wind speed, sunshine hours, and atmospheric pressure) in two typical stations (Maqu site and Minxian site) were selected to analyze the impacts on changes of ET and PET. Results of main climatic factors changes are shown in Figure 14. It was obvious that average temperature had a significant increasing trend, while sunshine hours, wind speed, and atmospheric pressure experienced decline-rise trends. Correspondingly, increase of ET was mainly caused by the average temperature rise, which was consistent with Cheng et al.'s [25] conclusions that the temperature had a significant increasing trend with a rate of $0.26^{\circ} \mathrm{C} / 10 \mathrm{a}(1956-2014)$ in the upper Taohe River basin. Furtherly, the increase of temperature and ET may have caused the decrease runoff directly and thus exacerbated water resources shortages in whole basin.
Generally, the increase in PET is expected as a consequence of global warming [44]. However, this study concluded that PET has been shown to decrease, which was consistent with the results in most places of China, like Tibetan Plateau and northwestern China [45]. Meanwhile, there were several studies reporting that PET was increasing in the source of Yellow River and Yangtze River basin $[32,46]$. Such contrast has been known as "evaporation paradox" and it is a very important scientific problem [47]. The reason remains a source of debate as climatic factors vary greatly in different regions in addition to possible interactions between climatic factors [48]. In terms of the reasons for PET decline, Wang et al. [49] found that the declined solar radiation and wind speed could be the main climatic factors. Similarly, this study found that the changes of sunshine hours, wind speed, and atmospheric pressure increased first and then decreased fluctuatedly, which might cause the decreasing pattern of PET in upper Taohe River basin. In summary, changes of ET and PET were predominantly driven by climate factors in upper Taohe River basin.

5.3. The Relationship between ET and PET. The relationship between ET and PET under climate warming background is an important scientific issue for the study of climate and hydrology [50]. There are two classical theories interpreting the interaction and difference between ET and PET. On one hand, Penman [51] believed that change of PET is in proportion to ET when the water supply is insufficient, and the function relation between PET and ET depends on water validity including soil water and plant conditions. This is the most famous expression of "proportional hypothesis theory." On the other hand, Bouchet [52] proposed regional complementary correlation theory between ET and PET and defined wet environment areal evapotranspiration (Ew) as the assumed evapotranspiration in stable conditions of constant external energy, adequate water, and homogeneous surface. Based on the hypothesis of advection except constant external energy, ET decreases along with the decline of soil water and the remaining energy, which would be added to PET increase. Generally, the proportional hypothesis theory and complementary correlation theory are completely in contrast in form, and the variations of ET and PET can only fit one of these theories. Results in this study 


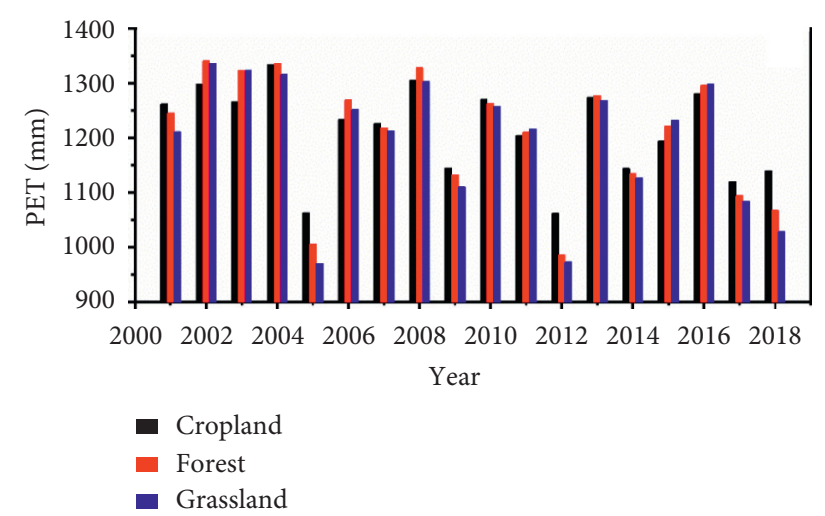

(a)

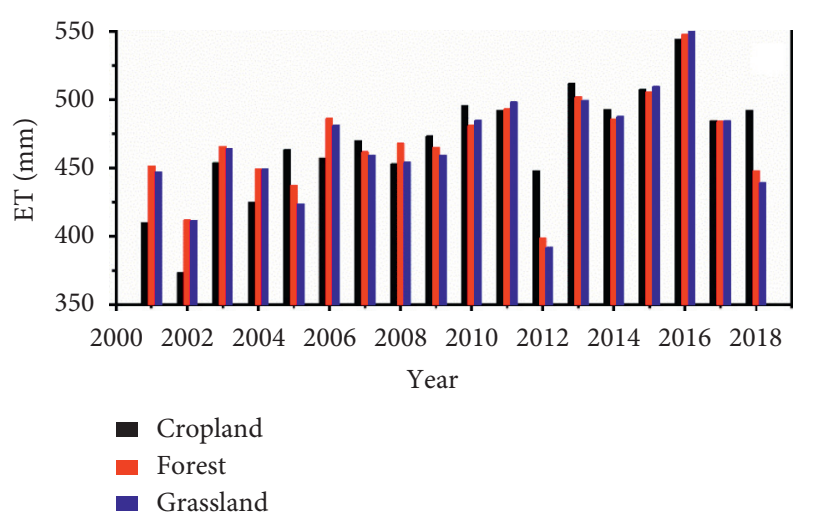

(b)

Figure 12: Changes of annual PET (a) and ET (b) in different land use over the upper Taohe River basin from 2001 to 2018.

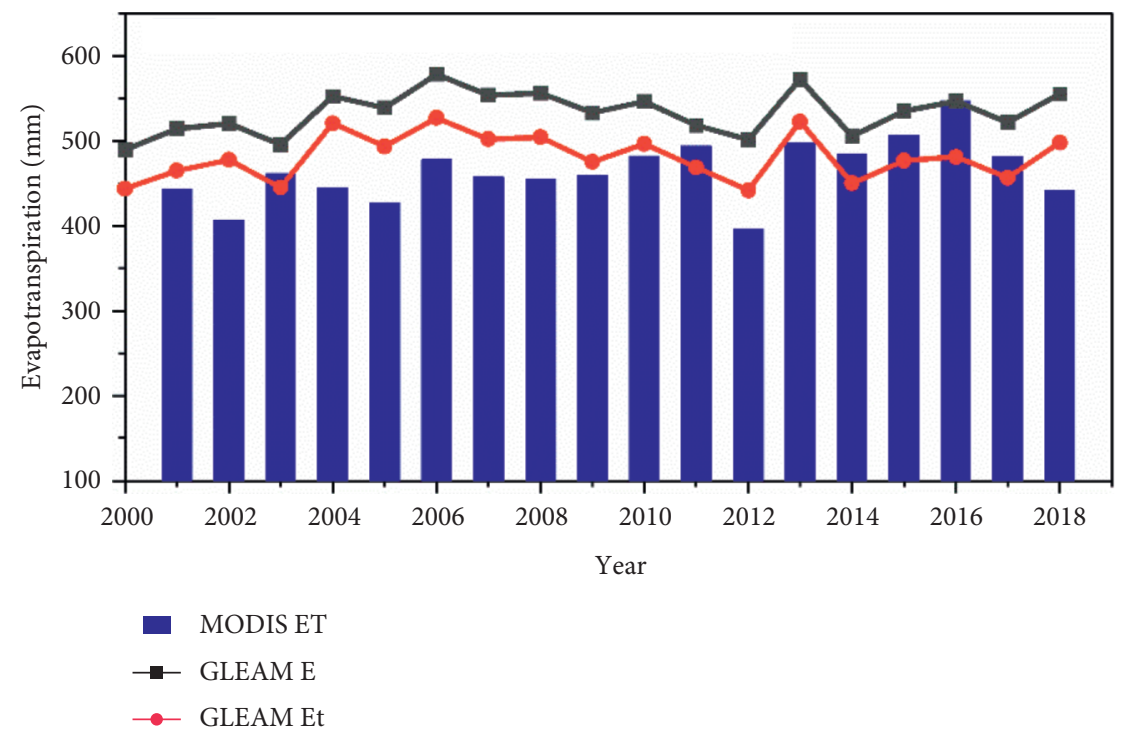

FIgURE 13: The change of evapotranspiration by GLEAM data and comparison with MODIS data from 2001 to 2018 in upper Taohe River basin.

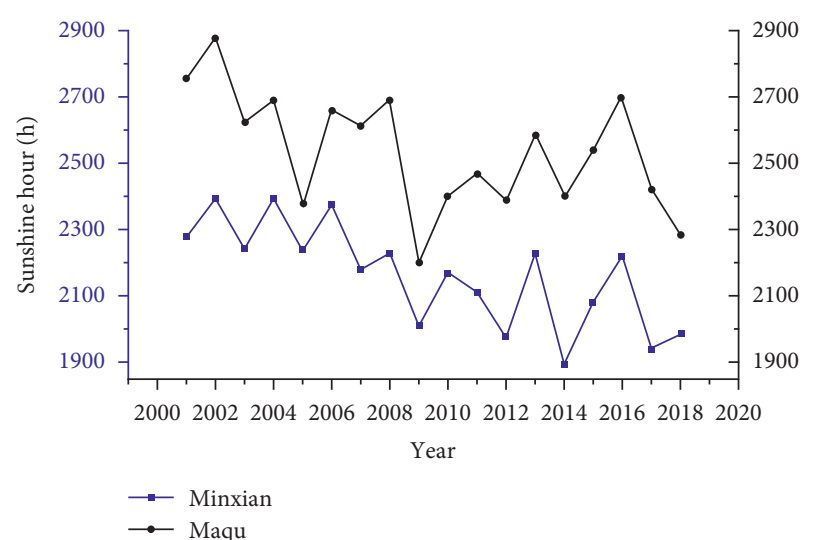

(a)

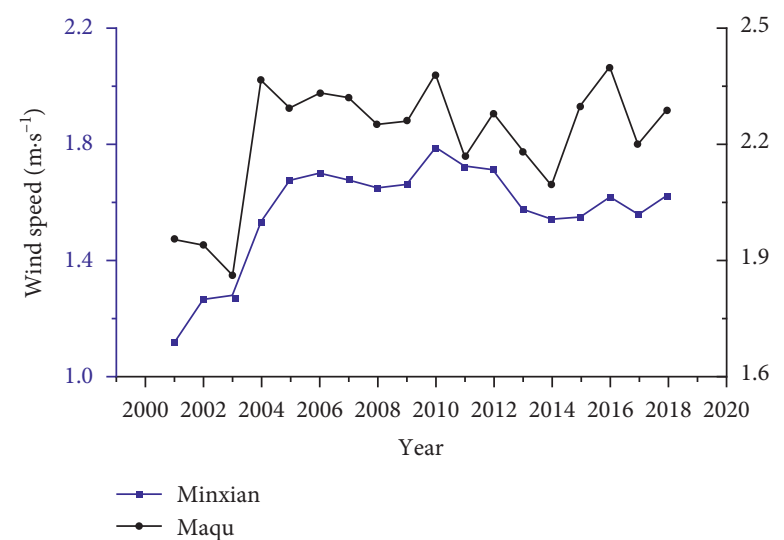

(b)

Figure 14: Continued. 


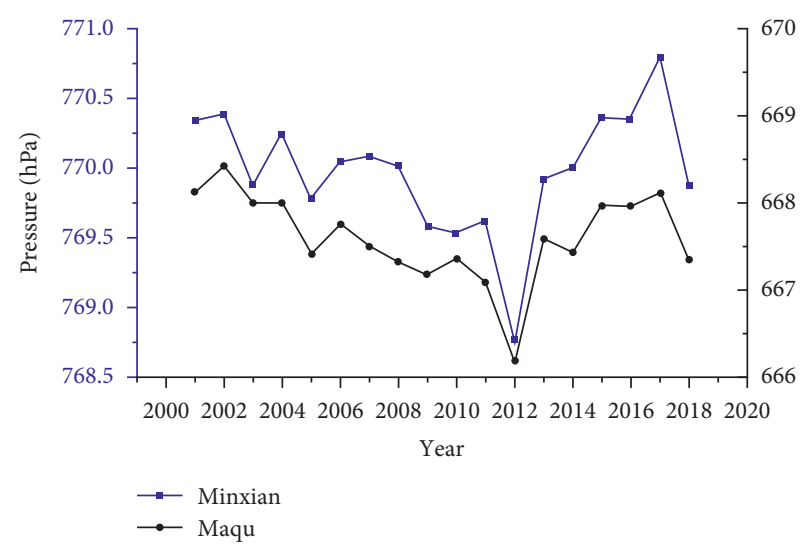

(c)

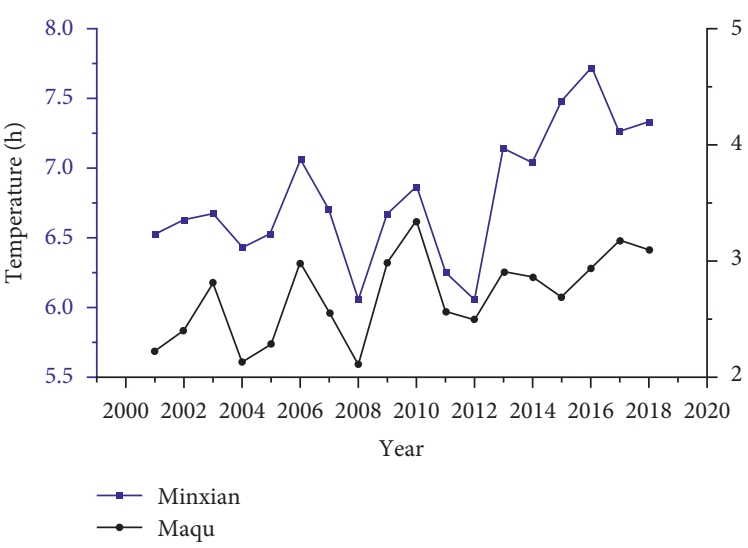

(d)

Figure 14: Changes of main climatic factors in Maqu and Minxian stations over the upper Taohe River basin from 2001 to 2018.

showed that ET was increasing, while PET was decreasing in upper Taohe River basin, and the contrast tendency between ET and PET in accordance with Bouchet's complementary theory.

In addition, many researchers had proved that complementary correlation theory was more applicable to nonhumid areas [53]. The semiarid and arid regions in Northwest China are sensitive to climate changes owing to the unique geographical conditions [54-56]. Shortage of water resource has adversely affected the sustainability of ecological system and social and economic development in the semiarid and arid areas. Taohe River basin lies in the transition zone of the two major geomorphic units of China, Qinghai-Tibet Plateau and Loess Plateau, which makes it more crucial to understand how hydrological circle responds to climate systems. Therefore, related research considering water balance in the semiarid and arid areas will be carried out further in the future.

\section{Conclusions}

Evapotranspiration is a key parameter of global hydrological cycle. This study analyzed the spatial and temporal characteristics of ET and PET and also explored impacts of landuse types and climate factors based on MODIS MOD16 ET data in the upper Taohe River basin during 2001-2018. The main conclusions can be drawn as follows:

(1) MODIS ET data well captured the seasonal variability with WBET, and good accuracy was obtained from evaluation analysis, which provided support to spatial and temporal characteristics of ET and PET furtherly.

(2) Based on MOD16 data, annual ET showed a significant increasing trend with a rate of $3.48 \mathrm{~mm} / \mathrm{a}$ from 2001 to 2018, while PET experienced a decreasing trend at a rate of $-8.18 \mathrm{~mm} / \mathrm{a}$. The seasonal distributions of ET and PET were uneven. The interannual change of ET was mainly caused by the rise of ET in spring and summer; similar to ET, the change of PET from the largest to the smallest was summer $>$ autumn $>$ winter $>$ spring. The spatial distribution of ET and PET showed the distribution characteristics of being high in the northern zone and low in the southern zone.

(3) Grass land was the major land use in the study area and the changes of land use were insignificant over the whole basin during 2001-2018. ET changes in cropland were significant, while PET changes in cropland were insignificant. The PET reductions in grass and forest were $141.03 \mathrm{~mm}$ and $135.85 \mathrm{~mm}$, which were decreased by $10.75 \%$ and $10.47 \%$, respectively.

(4) ET increase was mainly caused by the average temperature rise, while the decline-rise trends of sunshine hours, wind speed, and atmospheric pressure caused the decreasing pattern of PET. Therefore, changes of ET and PET were predominantly driven by climate factors in upper Taohe River basin.

\section{Data Availability}

The MODIS MOD16 data used to support the findings of this study are included within the article. MODIS data are provided by Numerical Terradynamic Simulation Group (NTSG) of the University of Montana, USA (http://www. ntsg.umt.edu/project/mod16\#data-product).

\section{Conflicts of Interest}

The authors declare that they have no conflicts of interest.

\section{Acknowledgments}

This work was supported by the National Natural Science Foundation of China (41771068, 41601077, and 41571066), the Strategic Priority Research Program of the Chinese Academy of Sciences (CAS) (XDA19070204 and XDA20100102), the Second Tibetan Plateau Scientific Expedition and Research Program (STEP) (2019QZKK0208), 
the CAS "Light of West China" Program, and the Youth Innovation Promotion Association CAS (2018460).

\section{References}

[1] K. C. Wang and R. E. Dickinson, "A review of global terrestrial evapotranspiration: observation, modeling, climatology, and climatic variability," Reviews of Geophysics, vol. 50, no. 2, pp. 1-54, 2012.

[2] Y. Chang, Y. Ding, Q. Zhao, and S. Zhang, "Remote estimation of terrestrial evapotranspiration by Landsat 5 TM and the SEBAL model in cold and high-altitude regions: a case study of the upper reach of the Shule River Basin, China," Hydrological Processes, vol. 31, no. 3, pp. 514-524, 2017.

[3] C. Zhang, D. Zhang, X. Liu, and C. Zhao, "Spatial and temporal change in the potential evapotranspiration sensitivity to meteorological factors in China (1960-2007)," Journal of Geographical Sciences, vol. 22, no. 1, pp. 3-14, 2012.

[4] X. Zhao, S. Peng, W. Wang, J. Xu, and S. Yang, "Spatial and temporal distribution characteristics of reference evapotranspiration trends in Karst area: a case study in Guizhou Province, China," Meteorology and Atmospheric Physics, vol. 128, no. 5, pp. 677-688, 2016.

[5] G. Xu, E. Bekoe, J. Ampofo et al., "New alternatives for reference evapotranspiration estimation in West Africa using limited weather data and ancillary data supply strategies," Theoretical and Applied Climatology, vol. 132, no. 3-4, pp. 701-716, 2017.

[6] G. Gao, D. L. Chen, and G. Y. Ren, "Trend of potential evapotranspiration over China during 1956 to 2000," Geographical Research, vol. 25, no. 3, pp. 378-387, 2006.

[7] G. Gao, D. Chen, C.-Y. Xu, and E. Simelton, "Trend of estimated actual evapotranspiration over China during 1960-2002," Journal of Geophysical Research, vol. 112, no. D11, p. D11120, 2007.

[8] W. Simelton and A. M. Melesse, Evaporation and Evapotranspiration: Measurements and Estimations, p. 206, Springer, London, UK, 2013.

[9] K. Wang and S. Liang, "An improved method for estimating global evapotranspiration based on satellite determination of surface net radiation, vegetation index, temperature, and soil moisture," Journal of Hydrometeorology, vol. 9, no. 4, pp. 712-727, 2008.

[10] M. Choi, W. P. Kustas, and R. L. Ray, "Evapotranspiration models of different complexity for multiple land cover types," Hydrological Processes, vol. 26, no. 19, pp. 2962-2972, 2011.

[11] K. Zhang, J. S. Kimball, and S. W. Running, "A review of remote sensing based actual evapotranspiration estimation," Wiley Interdisciplinary Reviews: Water, vol. 3, no. 6, pp. 834-853, 2016.

[12] O. F. Olabode, "Potential groundwater recharge sites mapping in a typical basement terrain: a GIS methodology approach," Journal of Geovisualization and Spatial Analysis, vol. 3, p. 5, 2019.

[13] W. G. M. Bastianssen, M. Menenti, and A. A. M. Holtslag, “A remote sensing surface energy balance algorithm for land (SEBAL). 1. Formulation," Journal of Hydrology, vol. 212-213, pp. 198-212, 1998.

[14] H. W. Kim, K. Hwang, Q. Mu, S. O. Lee, and M. Choi, "Validation of MODIS 16 global terrestrial evapotranspiration products in various climates and land cover types in Asia," KSCE Journal of Civil Engineering, vol. 16, no. 2, pp. 229-238, 2012.
[15] H. A. Lee, R. Leuning, Q. Mu, and S. W. Running, "Regional evaporation estimates from flux tower and MODIS satellite data," Remote Sensing of Environment, vol. 106, no. 3, pp. 285-304, 2007.

[16] A. L. Running, K. J. Franz, and T. S. Hogue, "Case studies of a MODIS-based potential evapotranspiration input to the sacramento soil moisture accounting model," Journal of Hydrometeorology, vol. 18, no. 1, pp. 151-158, 2017.

[17] J. Du and K. Song, "Validation of global evapotranspiration product (MOD16) using flux tower data from Panjin coastal wetland, northeast China," Chinese Geographical Science, vol. 28, no. 3, pp. 420-429, 2018.

[18] Y. Chen, J. Xia, S. Liang et al., "Comparison of satellite-based evapotranspiration models over terrestrial ecosystems in China," Remote Sensing of Environment, vol. 140, pp. 279-293, 2014.

[19] R. D. Q. Feng, J. D. Galvíncio, M. S. B. D. Moura, C. A. Jones, and R. Srinivasan, "Reliability of MODIS evapotranspiration products for heterogeneous dry forest: a study case of Caatinga," Advances in Meteorology, vol. 2017, Article ID 9314801, 14 pages, 2017.

[20] Z. Jones, Q. Wang, Z. Ouyang, M. Watanabe, B. Matsushita, and T. Fukushima, "Evaluation of MOD16 algorithm using MODIS and ground observational data in winter wheat field in North China Plain," Hydrological Processes, vol. 21, no. 9, pp. 1196-1206, 2007.

[21] Z.-Z. Ma, R. L. Ray, and Y.-P. He, "Assessing the spatiotemporal distributions of evapotranspiration in the Three Gorges Reservoir Region of China using remote sensing data," Journal of Mountain Science, vol. 15, no. 12, pp. 2676-2692, 2018.

[22] Q. F. Wang, J. Tang, J.-Y. Zeng et al., "Spatial-temporal evolution of vegetation evapotranspiration in Hebei Province, China," Journal of Integrative Agriculture, vol. 17, no. 9, pp. 2107-2117, 2018.

[23] C. B. Li, S. B. Wang, L. S. Yang et al., "Spatial and temporal variation of main hydrologic meteorological elements in the Taohe River Basin from 1951 to 2010," Journal of Glaciology and Geocryology, vol. 35, no. 5, pp. 1259-1266, 2013, in Chinese.

[24] C. Li, J. Qi, L. Yang et al., "Regional vegetation dynamics and its response to climate change-a case study in the Tao River Basin in Northwestern China," Environmental Research Letters, vol. 9, no. 12, Article ID 125003, 2014.

[25] L. Z. Cheng, L. J. Ma, M. X. Yang, G. Wan, and X. Wang, "Changes of temperature and precipitation and their impacts on runoff in the upper Taohe River in Northwest China from 1956 to 2014," Environmental Earth Sciences, vol. 78, p. 423, 2019.

[26] X. Wang, G. Pang, and M. Yang, "Precipitation over the Tibetan Plateau during recent decades: a review based on observations and simulations," International Journal of Climatology, vol. 38, no. 3, pp. 1116-1131, 2018.

[27] Z. M. Mu, F. A. Heinsch, M. Zhao, and S. W. Running, "Development of a global evapotranspiration algorithm based on MODIS and global meteorology data," Remote Sensing of Environment, vol. 111, no. 4, pp. 519-536, 2007.

[28] Z. M. Mu, M. Zhao, and S. W. Running, "Improvements to a MODIS global terrestrial evapotranspiration algorithm," Remote Sensing of Environment, vol. 115, no. 8, pp. 1781-1800, 2011.

[29] L. Z. Cheng, M. X. Yang, X. J. Wang et al., "Analysis of the accuracy of TRMM 3B42 rainfall data in the upper and middle 
reaches of Taohe River," Plateau Meteorology, vol. 39, no. 1, pp. 185-195, 2020, in Chinese.

[30] D. G. Miralles, T. R. H. Holmes, R. A. M. De Jeu, J. H. Gash, A. G. C. A. Meesters, and A. J. Dolman, "Global land-surface evaporation estimated from satellite-based observations," Hydrology and Earth System Sciences Discussions, vol. 7, no. 5, pp. 8479-8519, 2010.

[31] C. Zhao and S. H. Chen, "Spatiotemporal variations of evapotranspiration and potential evapotranspiration in Shandong Province based on station observations and MOD16," Progress in Geography, vol. 8, no. 36, pp. 1040-1047, 2017, in Chinese.

[32] H. Ye, T. B. Zhang, G. H. Yi et al., "Spatio-temporal characteristics of evapotranspiration and its relationship with climate factors in the source region of the Yellow River from 2000 to 2014," Acta Geographica Sinca, vol. 73, no. 11, pp. 2117-2134, 2018, in Chinese.

[33] W. Liu, L. Wang, J. Zhou et al., "A worldwide evaluation of basin-scale evapotranspiration estimates against the water balance method," Journal of Hydrology, vol. 538, pp. 82-95, 2016.

[34] D. W. Yang, F. B. Sun, Z. Y. Liu, Z. Cong, and Z. Lei, "Interpreting the complementary relationship in non-humid environments based on the Budyko and Penman hypotheses," Geophysical Research Letters, vol. 33, no. 18, pp. 122-140, 2006.

[35] H. B. Mann, "Nonparametric tests against trend," Econometrica, vol. 13, no. 3, pp. 245-259, 1945.

[36] M. Kendall, Rank Correlation Methods, Hafner Publishing Company, New York, NY, USA, 1948.

[37] K. G. Ghosh, "Analysis of rainfall trends and its spatial patterns during the last century over the Gangetic West Bengal, Eastern India," Journal of Geovisualization and Spatial Analysis, vol. 2, no. 15, 2018.

[38] P. K. Sen, "Estimates of the regression coefficient based on Kendall's Tau," Journal of the American Statistical Association, vol. 63, no. 324, pp. 1379-1389, 1968.

[39] G. Y. Hu, H. J. Jin, Z. B. Dong et al., "Research of land-use and land-cover change (LUCC) in the source regions of the Yellow River," Journal of Glaciology and Geocryology, vol. 36, no. 3, pp. 573-581, 2014, in Chinese.

[40] H. Achour, A. Toujani, T. Rzigui, and S. Faïz, "Forest cover in Tunisia before and after the 2011 Tunisian Revolution: a spatial analysis approach," Journal of Geovisualization and Spatial Analysis, vol. 2, no. 10, 2018.

[41] G. Newman, J. B. Hollander, J. Lee et al., "Smarter shrinkage: a neighborhood-scaled rightsizing strategy based on land use dynamics," Journal of Geovisualization and Spatial Analysis, vol. 2, no. 2, 2018.

[42] Y. Wang, X. Li, F. Shi, S. Zhang, and X. Wu, "The grain for green project intensifies evapotranspiration in the revegetation area of the Loess Plateau in China," Chinese Science Bulletin, vol. 64, no. 5-6, pp. 588-589, 2019, in Chinese.

[43] IPCC, Climate Change 2013: The Physical Science Basis. Contribution of Working Group I to the Fifth Assessment Report of IPCC, Cambridge University Press, Cambridge, UK; New York, USA, 2013.

[44] M. L. Roderick and G. D. Farquhar, "The cause of decreased pan evaporation over the past 50 years," Science, vol. 298, no. 5597, pp. 1410-1411, 2002.

[45] Y. Yang, S. Shang, and L. Jiang, "Remote sensing temporal and spatial patterns of evapotranspiration and the responses to water management in a large irrigation district of North
China," Agricultural and Forest Meteorology, vol. 164, pp. 112-122, 2012.

[46] L. Gong, C.-Y. Xu, D. Chen, S. Halldin, and Y. D. Chen, "Sensitivity of the Penman-Monteith reference evapotranspiration to key climatic variables in the Changjiang (Yangtze River) basin," Journal of Hydrology, vol. 329, no. 3-4, pp. 620-629, 2006.

[47] W. Brutsaert and M. B. Parlange, "Hydrologic cycle explains the evaporation paradox," Nature, vol. 396, no. 6706, p. 30, 1998.

[48] M. Jung, M. Reichstein, P. Ciais et al., "Recent decline in the global land evapotranspiration trend due to limited moisture supply," Nature, vol. 467, no. 7318, pp. 951-954, 2010.

[49] Z. Wang, P. Xie, C. Lai et al., "Spatiotemporal variability of reference evapotranspiration and contributing climatic factors in China during 1961-2013," Journal of Hydrology, vol. 544, pp. 97-108, 2017.

[50] L. L. Chen and G. Y. Zhang, "Relationship between actual evapotranspiration and potential evapotranspiration in Guangdong," Journal of Guangdong Ocean University, vol. 33, no. 3, pp. 71-77, 2013, in Chinese.

[51] H. L. Penman, "Natural evaporation from open water, bare soil and grass," Proceedings of the Royal Society of London. Series A. Mathematical and Physical Sciences, vol. 193, pp. 120-146, 1948.

[52] R. J. Bouchet, "Evapotranspiration reelet potentielle, signification climatique," International Association of Hydrological Sciences, vol. 62, pp. 134-142, 1963.

[53] Y. Wang, B. Liu, B. Su et al., "Trends of calculated and simulated Actual Evaporation in the Yangtze River Basin," Journal of Climate, vol. 24, pp. 4494-4507, 2011.

[54] Y. Chen, Z. Li, Y. Fan, H. Wang, and H. Deng, "Progress and prospects of climate change impacts on hydrology in the arid region of northwest China," Environmental Research, vol. 139, pp. 11-19, 2015.

[55] X. Wang, M. Yang, X. Liang et al., "The dramatic climate warming in the Qaidam Basin, northeastern Tibetan Plateau, during 1961-2010," International Journal of Climatology, vol. 34, no. 5, pp. 1524-1537, 2014.

[56] M. Yang, X. Wang, G. Pang, G. Wan, and Z. Liu, “The Tibetan Plateau cryosphere: observations and model simulations for current status and recent changes," Earth-Science Reviews, vol. 190, pp. 353-369, 2019. 